\title{
TESTIMONIATGE I MARTIRI EN LES CARTES DE FRA JACINTO ORFANELL, O.P., DES DEL JAPÓ (1609-1622)
}

\author{
Emi Turull Pibernat \\ Universitat Pompeu Fabra \\ Barcelona, Espanya \\ emitupi@gmail.com
}

Fra Jacinto Orfanell, de l'Orde de Predicadors, procedent del Convent de Santa Caterina a Barcelona, dominic màrtir, $i$ beat des del 1867, a principis del segle XVII va ser membre d'una de les missions dominiques que van participar en l'evangelització del Japó. Les cartes que ens consta que fra Orfanell va escriure durant els anys en què va viure en aquell país, afegides a les Relaciones, al Sumario de la vida del Santo Mártir, obra del seu germà franciscà, fra Joseph Orfanell, junt amb alguns Memorials relacionats, són el testimoni documental que ens serveix per presentar l'acció evangelitzadora al Japó de fra Jacinto Orfanell. L'article mostrarà com es va caracteritzar pel tema del martiri i per posar de manifest també la rivalitat existent entre els dominics i els jesuïtes en l'evangelització del país nipó, així com les diferències en el mètode d'adaptació cultural.

Paraules ClaU: Jacinto Orfanell; Cartes; Orde de Predicadors o Dominics; Evangelització del Japó; Martiri; Adaptació cultural; Rivalitat.

\section{Testimony And Martyrdom in the LetTers Written by Fra JaCinto ORfanell, O.P., FROM JAPAN (1609-1622)}

Fra Jacinto Orfanell, a friar of the Order of Preachers, from the Convent of Santa Caterina in Barcelona, a Dominican martyr and blessed from 1867, at the beginning of the 17th century became a member of one of the principal missions that carried out the evangelization of Japan. The letters written by Fra Orfanell from Japan during the years he served in that country, together with his Relations, the Summary of the life of the Holy Martyr, written by his Franciscan brother, Fr. Joseph Orfanell, as well as some related Memorials, constitute a documentary evidence that allows us to introduce the evangelizing action undertaken 
by Fr. Jacinto Orfanell, in which martyrdom was the central theme, and also to show the rivalry between Dominicans and Jesuits in the evangelization of Japan, as well as the differences in the method of cultural accommodation.

KEYWORDS: Jacinto Orfanell, Letters; Order of Preachers or Dominican Order; Evangelization of Japan; Martyrdom; Cultural Accommodation; Rivalry.

\section{Introducció}

La història de l'evangelització del Japó s'iniciava l'any 1549 amb l'arribada de Francesc Xavier, el primer jesuïta enviat a predicar fora d'Europa, pocs anys abans que, sota el patrocini espanyol, els ordes mendicants s'assentessin a les Filipines. Els agustins ho farien l'any 1564, seguits pels franciscans el 1576 i, finalment, els dominics el 1587. ${ }^{1}$ Així doncs, quan fra Jacinto Orfanell va arribar al Japó el 1607, els dominics ja feia cinc anys que hi havien establert la primera missió, després que el 1592 el dominic Juan Cobo arribés a Satsuma com a ambaixador del governador de Filipines, Gómez Pérez Dasmariñas, i, segons Boxer, ${ }^{2}$ que el 1602 el prior dels dominics a Manila, fra Francisco Morales, rebés la resposta afirmativa del daimyo ${ }^{-3}$ Shimazu Yoshihiro a la consulta per assentar una missió dels dominics en el seu feu. Per aquest primer establiment al Japó, a Kyōdomari, al Regne de Satsuma — d'on serien expulsats el 1609- van viatjar cinc frares dominics, entre els quals els PP. Alonso de Mena i Tomás Zumárraga, comandats pel P. Francisco Morales. D'aquesta manera, alguns dels anys en què fra Orfanell va dur a terme la seva missió evangelitzadora van coincidir amb els «anys de prosperitat» de la missió dels dominics al Japó, com indica el fet que entre el 1610 i el 1614 arribessin a tenir sis residències distribuïdes pel territori, ${ }^{4}$ cadascuna d'elles activa fins a la data assenyalada en el mapa, encara que el nombre total de missioners no fos mai superior a deu.

La finalitat d'aquest treball és analitzar les cartes que fra Orfanell va escriure des del Japó, com a testimoni d'una missió caracteritzada pel tema del martiri, tenint en compte que els dominics van arribar a la regió quan les autoritats japoneses ja havien fet un gir contrari al cristianisme, després que el 1587 els jesuïtes fossin expulsats, però sobretot, amb el punt d'inflexió que va suposar la condemna durant el mandat de Toyotomi Hideyoshi per la qual, el 5 de febrer de 1597, sis franciscans van ser crucificats junt amb vint persones més a conseqüència dels fets desencadenats pel naufragi del galió San Felipe. Així doncs, l'horitzó missioner va estar marcat, d'una banda, per les persecucions i els

1. Tronu, Carla, «The Rivalry between the Society of Jesus and the Mendicant Orders in Early Modern Nagasaki», Agora: Journal of International Center for Regional Studies, vol. 12, 2015, p. 25.

2. Boxer, C. R. i J. S. Cummins, The Dominican Mission in Japan (1602-1622) and Lope de Vega, Roma, Archivum Fratrum Praedicatorum, vol. XXXIII, 1963, p. 7.

3. Senyor feudal.

4. Muñoz, Honorio, «Los dominicos españoles en Japón (siglo XVII)», Separata de Missionalia hispánica, año XXII, núm. 64-65, Madrid, Raycar, 1965, p. 71. 
martiris que s'intensificarien a partir de l'edicte d'expulsió i de prohibició del cristianisme promulgat pel govern Tokugawa el gener de 1614 i, de l'altra, per les rivalitats originades en la defensa del monopoli jesuïta contra la pretensió dels ordes mendicants de predicar al Japó, encara que també per les maneres diferents d'adaptar-se a la cultura local. Així, el testimoni d'Orfanell permet entendre com es va viure aquella experiència.

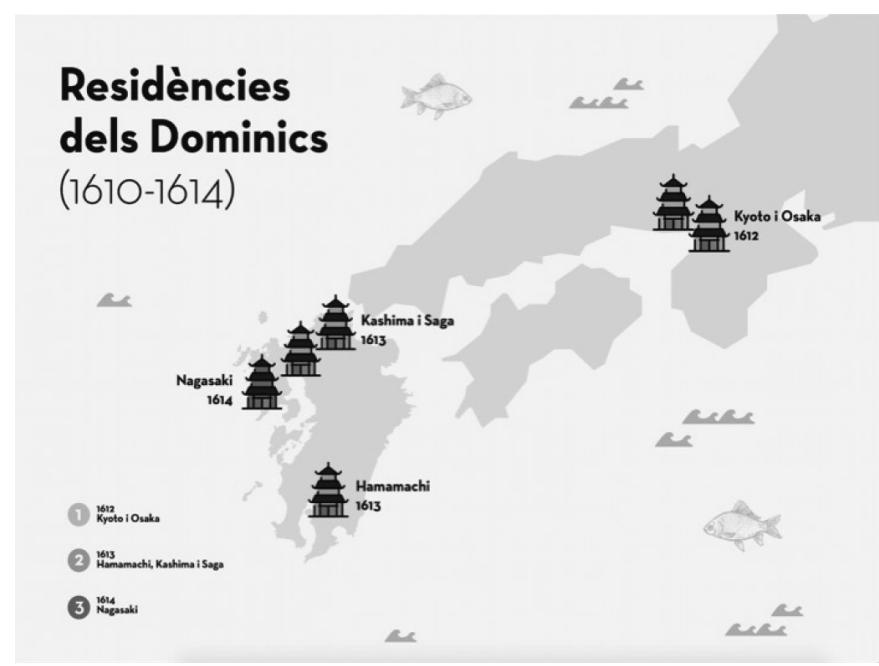

FONT: Elaboració pròpia.

\section{Fra Jacinto Orfanell (1578-1622) fins a l'arribada al Japó}

El dia 8 de novembre del 1578, a la vila de «La Jana maestrado de Montesa en el Reyno de Valencia»5 naixia fra Jacinto Orfanell, fill de Gaspar Orfanell i de Maria Salomé Prades. El van batejar amb el nom de Pere, segons consta a la partida de bateig: «A 8 Noembre de 1578 fonc batejat per mi mosèn Agostí Latzer, Pere, fill de Gaspar Orphanell y Magdalena». ${ }^{6}$ Un nom, que, en professar com a dominic, va canviar pel de Jacinto. ${ }^{7}$ Con-

5. Biblioteca de la Universitat de Barcelona (UB-R), Ms. 1008-1010, Gaspar Vicenç (compilador). Miscel-lània historicopolítica, vol. II, f. 244v-251v. «Sumario de la vida del santo mártyr fray Jacinto Orfanel», fol. $245 \mathrm{v}$.

6. Gargallo Valls, José, La Jana. I Centenario de la Beatificación de Jacinto Orfanell, La Jana, 1967, p. 68. [Libro de Bautismos, La Jana, años 1535-1717, fol. 36, v]. Si bé la mare aquí consta com a Magdalena, segons Joseph Orfanell, la seva mare es deia Maria Salomé Prades; això fa que ens preguntem si el nom complet no podria ser Maria Magdalena Salomé, perquè en el bateig catòlic era costum imposar tres noms als nounats, de manera que tant Maria Magdalena com Salomé serien vàlids. Orfanell, Joseph, UB-R, Ms. 1008-1010. vol. II, fol. $245 \mathrm{v}$.

7. Possiblement, el que va moure Pere Orfanell a canviar el seu nom pel de Jacinto va ser la devoció a sant Jacint de Polònia, compartida amb altres dominics per la freqüència amb què observem que a l'època triaven 
tinuant el relat fet l'any 1627 pel seu germà franciscà, fra Joseph Orfanell —nascut Mathias-, sabem que el pare havia estat comerciant i familiar del Sant Ofici. De la mare, tan sols ens consta que va morir jove i que Gaspar Orfanell es va tornar a casar l'any 1591 amb Càndida Boix. ${ }^{8}$ Així, els fills del primer matrimoni van ser Pere, Josep i Mariana i del segon, Mathias, Teudora i Maria. Dels sis germans, Pere — d'ara endavant Jacinto—, era el més gran de tots. Gaspar Orfanell va morir l'any 1600 i, com que no havia deixat testament, els sis fills van heretar la hisenda a parts iguals, «quatro mil y tantas libras y balgo más» ${ }^{9}$ cadascun; per tant, podem pensar que la família Orfanell en aquells temps era una família benestant.

Jacinto Orfanell, entre els 10 i 11 anys, va sortir de La Jana per anar a estudiar Gramàtica a la vila de Sant Mateu, capital històrica del Maestrat, a $10 \mathrm{~km}$ de distància, i al cap de quatre anys va continuar amb els estudis d'Arts a la ciutat de València. Al final d'aquella etapa se'n va anar a Alcalá d'Henares per estudiar Teologia. A causa d'una epidèmia de pesta que hi va haver en aquelles terres els anys 1597-98, va emmalaltir i va tornar cap a València primer, després a Lleida i, finalment, el 1600 ja va marxar cap al Convent de Santa Caterina de Barcelona. ${ }^{10}$ Allà va prendre els hàbits de dominic el 1r de març de l'any 1600, segons cita José Delgado O.P. ${ }^{11}$ que consta al Libro de tomas de hábito del Convento de Santa Catalina, Virgen y Mártir, de Barcelona, desde el 17 de noviembre de 1569 al 8 de mayo de 1631, n. 57, f. 121v:

1600. Fr. Giacinto Orfanell. Al primero de março de 1600 tomó el hábito para fraile de $c<b>$ oro Pedro Orfanell y mudóse el nombre en Hiacinto. Natural de la villa de la Jana, en el reyno de Valencia. Lo que traxo fue un ferregüelo largo usado, una sotanilla también usada, unos greguefus pardos, un jubón, el cual lo lleva, dos camisas, dos cuellos llanos, unos borseguines y unas medias negras viejas y sombrero, dos libros, un vitas fratrum y la primera parte de la bistoria de la Orden. ${ }^{12}$

aquest nom. Sant Jacint, polonès, va conèixer sant Domingo de Guzmán a Roma, i l'any 1220 va rebre de les seves mans l'hàbit dominicà. Va morir al convent de Cracòvia l'any 1257 i va ser primer beatificat el 1527, i després canonitzat per Clement VIII l'any 1594. Només set anys després, en el moment de professar, el 1601, Orfanell adoptava el nom de Jacinto.

8. Gargallo Valls, José, La Jana..., cit., p. 64.

9. UB-R, Ms. 1008-1010, vol. II, f. 246.

10. El Convent de Santa Caterina, verge i màrtir (Caterina d'Alexandria o Sta. Caterina de la roda), va ser un convent dels dominics establert a Barcelona entre els segles XIII i XIX.

11. En la historiografia de Jacinto Orfanell, destaca el dominic José Delgado, autor de «Beato Jacinto Orfanell O.P., religioso de la Provincia dominicana de Aragón: Cartas y Relaciones», Escritos del Vedat, vols. XIII-XIV, Torrente (València), Facultad de Teología de San Vicente Ferrer, 1983-1984. Delgado va transcriure, recopilar i anotar les cartes de Jacinto Orfanell, les Relaciones i també una part del Sumario de la vida de fra Orfanell. Segons ell mateix anota, les seves transcripcions es basen en els manuscrits originals, i en dóna les referències de classificació dins del fons de l'Antiguo Archivo Provincial de la Província del Santo Rosario a Manila (AAP), que es conserva a l'Archivo Provincial Dominicos de Ávila (APDA). Això no obstant, actualment els manuscrits originals no són consultables i, a més, hem pogut comprovar que algunes de les transcripcions que s'han fet, i que ofereixen com a alternativa a la consulta dels originals, són incorrectes.

12. Archivo Dominicano de la Província de Aragón, Valencia (ADV) citat a Delgado, José, Beato Jacinto..., cit., 1983, p. 325. 
D'acord amb el Llibre de les Professions dels Religiosos de Santa Catharina, V. i M., de Barcelona desde los anys 1531 fins al 1683, fol. 14, Orfanell va professar el dos de març del 1601:

Die 2 Martii 1601 ego Fr. Gaspar de Dio, praesentatus et prior buius Conventus, recepi ad professionem Fr. Hyacintum Orfanell, existentibus Priori Provinciali A.R.P. Fr. Hyeronimo Xavierre et Vicario Generali R.P.Fr. Stephano Mario Fr. Gaspar de Dio praesentatus et Prior. Nota: Reliquit conventui Fr. Hi. Orphanell 800 -A-q-, id est, 400 ex illis pro quibusdam aniversariis perpetuo celebrandis, alias vero 400 ad Latrinas perficiendas, quibus maxime indigebat domus baec. ${ }^{13}$

Des del 1601 fins al 1604, Orfanell va completar al Col·legi de la ciutat de Tortosa els estudis de Teologia. ${ }^{14}$ Finalitzats, el van enviar a Valladolid, on hi havia la Cort del rei Felip III, però un cop allà va tornar a emmalaltir, aquesta vegada de tifus. Ja restablert, va saber que a la Cort un Comissari de l'Orde, el P. Diego Aduarte, ${ }^{15}$ «juntava religiosos y soldados de Christo para la conquista de las almas de Philipinas y Japón». ${ }^{16} \mathrm{Va}$ arribar a un acord amb el Comissari dominic i fra Orfanell va tornar al Convent de Barcelona per rebre la benedicció i acomiadar-se dels qui havien estat els seus mestres i companys, així com del Col-legi de Tortosa. En resposta a l'encàrrec que havia rebut de reunir tres o quatre religiosos més de la Província i Corona d'Aragó, després de conduir-los fins a Sevilla, es va embarcar a San Lúcar de Barrameda, amb destí a Manila, amb una Missió de la Província del Santo Rosario de Filipines. ${ }^{17}$

13. ADV, n. 57, citat a Delgado, José, Beato Jacinto..., cit., 1983, p. 325. «El dia 2 de març jo fra Gaspar de Dio, doctorand en teologia i prior d'aquest convent, he rebut per a la professió fra Jacinto Orfanell, amb l'assistència del prior provincial A.R.P. fra Jeroni Xavierre i del vicari general R.P. fra Esteve Mario. Fra Gaspar de Dio, doctorand en teologia. Nota: Fra J. Orfanell va deixar al convent 800 -A-q- (lliures?): 400, de les quals són per a la celebració perpètua d'aniversaris, i les altres per fer les comunes (les latrines), que molt necessitava aquesta casa» [traducció pròpia].

14. UB-R, Ms. 1008-1010, vol. II, f. 246v. I segons afirma fra Joseph Orfanell: «donde estudió tres o quatro años, y salió tan consumado, que le ofrecían cathedra (según me dixeron algunos Padres de aquel Collegio) y él la dexó por yr a ensenyar a los infieles de Japón».

15. Delgado, José, Beato Jacinto..., cit., 1983, p. 327.

16. UB-R, Ms. 1008-1010, vol. II, f. 246v.

17. Sobre aquest punt hi ha una certa discrepància i confusió entre Delgado, José, Beato Jacinto..., cit., 1983, p. 328, que afirma que Orfanell es va embarcar a la Missió IX, que va sortir d'Espanya l'any 1605, i Ocio, Hilario, Compendio de la reseña biográfica de los Religiosos de la Provincia del Santísimo Rosario de Filipinas desde su fundación hasta nuestros días, Manila, 1895, p. 59, que inclou fra Orfanell a la Missió VIII, que va sortir d'Espanya l'any 1603 i va arribar a Manila al juny de 1604. Si tenim en compte que des del 1601 fins al 1604, Orfanell era al Col·legi de Tortosa, la seva participació en la Missió VIII no seria possible. D’altra banda, segons Ocio, la Missió IX havia estat promoguda pel P. Aduarte i va sortir d'Espanya a primers de juliol del 1605 per arribar a Manila a l'agost de 1606. Per tant, la hipòtesi que ens sembla més probable és que fra Orfanell hagués format part d'aquesta novena missió, i que per raó de malaltia va haver de quedar-se a Mèxic (des d'on al desembre de 1605 escriuria una primera carta al seu germà Joseph), i no arribaria al Japó fins l'any 1607. Per tant, i sempre seguint Ocio (pp. 68-77), els altres dominics que haurien format part de la novena missió, a més de Jacinto Orfanell, haurien estat: el beat José Salvanés de San Jacinto, fra Melchor Manzano, fra Domingo Vicente, fra Lorenzo Porras, fra Vicente Alfonso, fra García Oroz, fra Pedro Gómez, fra Mateo de la Villa, fra Gaspar Casablanca, fra Martín de la Anunciación, fra Francisco de Cabrera, fra Jacinto López de San Jerónimo, fra Luís García, fra Andrés de Velasco, fra Jerónimo Catalán, fra Tomás Herla, fra Tomás Piquer, fra Jacinto 
Gràcies a les cartes que va enviar al seu germà Joseph ${ }^{18}$ en aquells primers anys, encara que algunes no es conservin, podem seguir el recorregut d'Orfanell. El 21 de desembre de 1605 li escrivia ja des de Mèxic. Allà, molt malalt, s'hi va estar durant dos anys, i per fi l'11 de març de 1607 es va poder embarcar cap a Filipines. Novament, durant el viatge, sembla que va tornar a caure malalt, però quan va arribar a Manila al mes de maig ja estava recuperat, d'acord amb una segona carta que va escriure al mateix germà el 25 de maig de 1607, ara ja des de Manila. ${ }^{19}$ D'allà va ser assignat a la Casa de Sto. Domingo y la Virgen del Rosario de Kyōdomari, al Japó. Fra Orfanell, a Historia eclesiástica... ${ }^{20}$ relatava la seva anada al Japó al juny de 1607:

...fueron los Padres fray Ioseph de san Iacinto, y fray Iacinto Orfanel, y el hermano fray Iuan de san Iacinto lego: embiólos el P. fr. Iuan de S. Tomás, Vicario Provincial que era a la sazón de Manila, por orden que tenía para ello del P. fr. Miguel de S. Iacinto Provincial, que estava ausente.

Els tres missioners es quedarien a la localitat de Kyōdomari, junt amb els PP. Francisco Morales i el superior Tomás del Espíritu Santo Zumárraga, que hi eren des de l'any 1602, ${ }^{21}$ fins que el 1609 els van expulsar del Regne de Satsuma. Durant aquells anys, els dominics, i per tant també fra Orfanell, es van poder dedicar a estudiar la llengua, les bones maneres i els costums japonesos. ${ }^{22}$

\section{Les cartes de Fra Orfanell des del 1609 fins al 1622}

Sembla generalment admès que el testimoni historiogràfic de fra Orfanell sobre el propòsit i les circumstàncies d'evangelització del Japó, duta a terme per l'orde dels dominics a principis del segle XVII, es basa de manera fonamental en la seva obra Historia Eclesiástica de la Christiandad de Iapón ${ }^{23}$ completada per fra Diego Collado. ${ }^{24}$ Això no obstant, les cartes que

Palau, fra Andrés Rada, fra Vicente de San Jacinto, fra Diego del Águila, fra Francisco Francín, els Germans fra Juan de San Jacinto, fra Francisco Rodríguez, fra Bartolomé Rodríguez i fra Antonio Vázquez.

18. Que no era el que després es faria franciscà i canviaria el nom de Mathias pel de Joseph.

19. Delgado, José, Beato Jacinto..., cit., 1983, p. 328.

20. Orfanel, Jacinto y Diego Collado, Historia eclesiástica de los sucessos de la christiandad de Iapón, Madrid, Viuda de Alonso Martín, 1633.

21. Muñoz, Honorio, Los dominicos..., cit., p. 68.

22. Boxer, C. R. i J. S. Cummins, The Dominican..., cit., p. 7.

23. D'entre les cròniques dels dominics més conegudes i estudiades, destaca aquesta obra d'Orfanell, Historia Eclesiástica de los sucessos de la Christiandad de Iapón, desde el año de 1602, que entró en él la Orden de Predicadores hasta el de 1620, que es publicaria l'any 1633, amb el Pròleg i el Suplement de deu capítols addicionals, obra de fra Diego Collado, O.P. En ella, Fra Orfanell relata el procés d'evangelització al Japó, referit al seu Orde en particular. Orfanell va fer grans esforços perquè la seva versió dels fets i dels martiris, conseqüència de les persecucions d'aquells anys, fos exacta i acurada. Un relat que, com afirma fra Diego Collado al Pròleg, en referir-se als fets: «no passarian por cosa que no fuesse muy verdadera, ni del Padre Fray Iacinto Orfanel solo (cuando no la huvieran visto, y aprovado otros) se puede entender que el escriviesse cosa que no buviesse visto, o supiesse muy claramente, por ser el dicho Padre muy modesto, verdadero, docto, y escrupuloso, y por ser tal, en las cosas que tocan en particular de su Orden, dize la verdad».

24. El dominic extremeny Fra Diego Collado —-segons Boxer, C. R. i J. S. Cummins, The Dominican..., 
Jacinto Orfanell va escriure a la família, als membres del convent de Santa Caterina —algunes d'elles recopilades per fra Gaspar Vicenç_ ${ }^{25} \mathrm{i}$ fins i tot algunes de les Relaciones que va adreçar als seus superiors, tenen valor històric per elles mateixes, sense que hagin estat prou estudiades, i són una part essencial del seu testimoni, per damunt de tot, perquè mostren un altre vessant d'Orfanell. En permetre's parlar en primera persona, creiem que s'hi expressava de manera més íntima i oberta, sobretot si tenim en compte allò que posava en evidència fra Diego Collado quan donava testimoni de com era Jacinto Orfanell: ${ }^{26}$

Gran enemigo de que se supiesse lo bueno que hazía. Y aunque escrivia la hystoria Ecclesiástica que dexó escrita de su mano, no buvo remedio de bazer con él, que se nombrasse en lo que escrivió tocante a su persona: y aún lo que tocava a nuestra Orden, no lo espicifcava mucho, diziendo que Dios pagaría lo bueno que hiziessemos, y no faltaría quien lo publicasse, que bastaría a la modestia religiosa dezir las cosas en común, y de aquella manera. $Y$ aún lo que escrivió, no lo buviera becho sino a puras importunaciones mias, y por orden de los Prelados.

\subsection{Carta al P. Rafael Rifós: 18 de febrer de $1609^{27}$}

Per primera vegada des de la seva arribada al Japó el 1607, Jacinto Orfanell va escriure al P. Rifós, prior del Convent de Santa Caterina de Barcelona, des de Sant Domingo de

cit., pp. 23-31—, va arribar al Japó el juliol de 1619, procedent de Filipines. Collado havia apressat Orfanell a escriure la Historia eclesiástica de... i, després que el beat fos arrestat, va creure que el seu deure era completar el treball amb un suplement (1620-1622). Fra Domingo Castellet i fra Collado van ser testimonis del Gran Martiri de Nagasaki del 10 de setembre de 1622, i els dos únics dominics espanyols supervivents. Així, el relat d'aquest martiri, que també va ser el de fra Orfanell, fra Collado l'inclou al capítol LXIX de la Historia eclesiástica de... Segons Arimura, Rie, «Las misiones católicas en Japón (1549-1639): análisis de las fuentes y tendencias historiográficas», Anales del Instituto de Investigaciones Estéticas, vol. 33, núm. 98, México, 2011, pp. 55106, Diego Collado és rellevant també per les aportacions que l'any 1632 va fer en el camp lingüístic en publicar Ars grammaticae iaponicae linguae. Seguint el relat de Boxer i Cummins, a finals del 1622, Collado va marxar cap a Manila per mirar d'aconseguir reforços per a la missió i, més tard, cap a Madrid i Roma per si podia obtenir més suport. El juny de 1635, va tornar a Manila, on es va trobar amb una gran oposició capitanejada per Fra Diego Aduarte, bisbe de Nueva Segovia. Davant la forta oposició, el 1638, Collado va salpar de manera clandestina cap a Europa, però el seu vaixell va naufragar i ell va morir ofegat.

25. Fra Gaspar Vicenç (1567-1648), dominic del Convent de Santa Caterina a Barcelona, va ser el compilador dels Ms.1008-1010 (UB-R), que conformen una Miscel-lània político-eclesiàstica. Aquests manuscrits inclouen un extens epistolari i descripcions de vivències d'alguns religiosos mendicants, amb notes i resums al marge, probablement autògrafs del mateix fra Vicenç i d'altres. De les nou cartes d'Orfanell que avui dia coneixem, quatre formen part d'aquest epistolari.

26. UB-R, Ms. 1008-1010, vol. II, f. 248v-249. S'hi inclou el text segons el qual Fra Serafino Sicci, Mestre General de l'Orde Dominicana, comissiona el pare dominic fra Pere Joan Saragoça de Heredia, perquè amb el suport de fra Jordi Ximenez com a notari, obtingui del dominic fra Diego Collado, acabat d'arribar del Japó, una relació de la vida i mort de Fra Orfanell.

27. Ibidem, vol. I, f. 196-197v. El compilador Gaspar Vicens hi va anotar: «Fue recibida en el año de 1613». Els quatre anys transcorreguts des del 1609 evidencien el temps que podia passar des de l'enviament d'una carta fins que no arribava a destí. 
Quiondomari y regne de [Kyōdomari] Satsuma. Hi exposava algunes de les circumstàncies del viatge i també el retard amb què va arribar a Filipines: «que el precedente me quedé en nueva España, que es la metad del camino, con una grave enfermedad». Com ja hem vist, l'estat de salut de fra Orfanell era malaltís i, malgrat les recuperacions puntuals, requeia de manera recurrent. A Filipines, es va trobar amb «el hermano fray Andrés de Prada, que salió de essa casa, y el hermano fray Jacinto Palou de Girona, los quales tienen salud», i afegia que: «A mí, en llegando me embió la obediencia a Japón, donde solos estamos siete religiosos de la Orden de Predicadores». Els qui havien viatjat amb ell, el P. José de San Jacinto (Salvanés) i el germà llec Juan de San Jacinto — que el 1611 se'n tornaria cap a Manila-, es van sumar als tres primers dominics que ja eren al Japó des de l'any 1602, els PP. Francisco Morales, Alonso de Mena i Tomás del Espíritu Santo Zumárraga. A més, hi havia Juan de los Angeles Rueda, que hi havia arribat el $1604 .^{28}$

Fra Orfanell destacava també les dificultats per dur a terme la tasca evangelitzadora, a causa de la persecució que determinats senyors havien emprès contra els cristians, i això li servia des dels primers paràgrafs per compartir amb voluntat d'edificació la notícia del martiri recent d'un cristià japonès: «Unas muy sabrosas nuevas, y son que en este profundo de gentilidad nos a querido dar el Señor un santo mártyr». Es tractava del primer màrtir japonès dels dominics al Japó, al qual fra Orfanell havia batejat el 22 de juliol del 1608, ${ }^{29}$ imposant-li el nom de Leon Saisho Shichiemon.

Com un incís, dins d'un llarg parèntesi, en ser tan sols set dominics i amb tanta acció missionera per fer, introduïa una petició perquè des del Convent els enviessin reforços:

Si V.P. nos embiasse algunos religiosos dessa santa casa y tierra, fueramos escondidamente y a sombra de tejado a animar a los caýdos y confessar y esforçar, a ellos y a los demás; pero a penas podemos acudir a los christianos nuestros, que aunque son pocos, los ministros son poquíssimos y assi se haze raramente.

Continuava explicant les circumstàncies en què el soldat Shichiemon havia estat perseguit per haver-se fet cristià en uns anys en què la conversió de nobles i samurais estava prohibida i castigada amb la pena de mort. En aquella zona, el budisme estava molt arrelat i els habitants eren molt lleials al seu daimyō; per això, quan el senyor, Hongo Sakuyemon Mitsuhisa, governador del castell de Hirasa, ${ }^{30}$ va exigir a León Saisho Shichiemon que renunciés al cristianisme i ell s'hi va negar, en haver transgredit la prohibició, el 17 de novembre del 1608, segons explicava fra Orfanell, «le fue cortada la cabeça por no aver querido faltar en la fe que avia recebido bien poco avía: porque el día de la Madalena antes se avia becho christiano aqui en casa».

Tot seguit, es posa de manifest un interès molt gran per aconseguir els cossos dels màrtirs amb la voluntat d'obtenir relíquies, especialment les d'aquell primer màrtir, del

28. Muñoz, Honorio, Los dominicos..., cit., pp. 225-226.

29. UB-R. Ms. 1008-1010, vol. II, f. 252v.

30. Delgado, José, Beato Jacinto..., cit., 1983, p. 344. 
qual «el cuerpo no le quisieron dar, pero unos christianos le burtaron de noche de alli a tres dias y assí le tenemos en nuestra casa» i, com detalla encara més a Historia Eclesiástica, «repartiendo algunos pedazitos de la ropa del mártyr con los que le avían traído». ${ }^{31}$

A la carta, Fra Orfanell també comparava les formes d'evangelització de Manila i Japó: «Una es de gente senzilla y que van a buscar ministros para que les hagan christianos, como es en la tierra de Manila: y otra ay más dificultosa, que es ésta de Japón». Per a Orfanell, una de les grans dificultats eren els bonzos i el gran nombre de convents que tenien, alguns molt a prop de la seva església, Nuestra Señora del Rosario, situada dalt d'un turó als afores de la població de Kyōdomari. ${ }^{32}$ Els dos temples budistes més propers eren tant a tocar que es podia sentir com els monjos resaven de dia i de nit. Orfanell, a més de destacar la puntualitat dels bonzos, feia aquesta descripció dels seus temples i també del seu hàbit:

entrando en ellos, es entrar en un paraýso, por tenerlos muy curiosos con arbolicos y flores, siendo como son un infierno de demonios. El hábito que llevan es como el nuestro en el color blanco dentro, y fuera negro, aunque la forma es muy diferente.

Tanmateix, en allò que feia més èmfasi era en la idolatria, alhora que els qualificava com «un infierno de demonios», sense fer cap referència aprofundida a la seva doctrina.

Las sectas, con que el enemigo les tiene engañados son ventiquatro. ${ }^{33}$ Cada uno va por su camino. Unos bonzos enseñan que ay salvación: otros que no (y ésta es la más común). Otros, que esto es bueno bazerlo aunque sea abominable; otros que no, cada uno con sus disparates. Dios les abra los ojos, y a mi me haga buen ministro para que pueda dar buena cuenta de lo que se me a encomendado.

Orfanell s'acomiadava dient que en el moment d'acabar la carta li havien arribat notícies de la mort de quatre cristians al Regne de Fingo.

\subsection{Carta al seu germà Joseph Orfanell des de Kyōdomari: 22 de febrer de $1609^{34}$}

La tercera carta d'Orfanell adreçada al seu germà Joseph (1580-1611), de la qual tan sols ens consta la transcripció publicada per J. Gargallo, sembla que va ser escrita només quatre dies després de la que va adreçar al P. Rifós. Hi ha algunes referències que són pràcticament iguals, com ara l'estada a Mèxic per malaltia i la data d'arribada al Japó:

31. Orfanel, Jacinto y Diego Collado, Historia eclesiástica..., cit., f. 5.

32. Ibidem, f. 2.

33. Probablement es tracta d'una exageració retòrica.

34. Joaquín García, descendent de la família Orfanell, a La Jana, en conservava l'original manuscrit que José Gargallo afirma haver vist i copiat. Així, el meu comentari està basat en Gargallo Valls, José, La Jana ..., cit., pp. 74-79, editat amb motiu del Centenari de la beatificació de Jacinto Orfanell. 
«Ahora estoy en Xapón, en donde solo somos de nuestra Orden siete religiosos, aunque de $S$. Francisco y de la Compañia hay muchos más en diversos reinos». Tornava a referir-se a la proximitat als temples budistes, la persecució a què estaven sotmesos els cristians i el martiri de León. Ara bé, tant en la intenció com pel to i la forma amb què Orfanell s'expressava, aquesta nova carta és ben diferent.

En el primer paràgraf mostrava la seva determinació: «que lo que yo os dixere lo tomáreis como de un bermano que os ama en el alma; quizá abi no tendréis quien lo haga, sinó quien os ayude a perder y ésto sólo me mueve ahora a escribiros». Després d'algunes preguntes retòriques, insistia i es mostrava profundament preocupat pel tipus de vida que creia que duia el seu germà:

entré de golpe en esto por ser lo que más pretendo escribiros, como quien sólo desea desengañaros y daros el más importante aviso que amigo ninguno os pueda dar y abriros los ojos, si acaso los tenéis encandilados en las cosas de este mundo y vivís olvidado de esta hora donde aunque más hagáis, heis de llegar; en la cual sólo os ha de pesar el no haber vivido bien, y el haber sido honrado y regalado, etc., os ha de causar tan gran pena que os haga aullar como perro y «así ésta ha sido la causa de escribiros esta carta», la cual no querría que os sirviese de otra cosa que de este aviso.

Amb to moralitzador, li donava consells com si el que pretengués fos provocar una catarsi de caràcter moral i, amb l'ajuda de cites de Sant Pau, de Salms i de l'Eclesiastés, busqués l'impacte en el seu germà. ${ }^{35}$ També li recomanava que llegís Fray Luís de Granada (1504-1588):

lo que os ruego encarecidamente y querría que en esto me consoláseis y que, pues tenéis los libros del P. F. Luis de Granada y si no los tenéis que los compréis, que leáis todos los dias un pedazo de la meditación de cada día.

I és que Orfanell tenia una predilecció especial per la Guía de pecadores. ${ }^{36}$

El dominic expressava també l'afecte que sentia per Càndida Boix, ${ }^{37}$ la segona esposa del seu pare, ja vídua, i la cura que creia que calia tenir-ne, sobretot per agraïment:

...os acordéis de nuestra madre cuando estudiábamos y como nos crió, que fué como a madre propia, todo por aviso. Si vive, dadle de mi parte un abrazo y que tome ésta por propia, que me encomiendo a Dios y tenga paciencia, que sus trabajos son dos días y el premio para siempre y yo quisiera hallarme junto para servirla lo mucho que le debo, pero que todo se cumplirá.

35. Joseph Orfanell va morir dos anys després, el 31 d'agost de 1611, als 31 anys, i podria ser que abans de rebre la carta.

36. Granada, Luís de (O.P.), Guia de pecadores, Manila, Iacinto Magarulau, 1631 [1551].

37. Delgado, José, Beato Jacinto..., cit., 1983, p. 351. Càndida Boix va néixer el 1565 i el 1591 es va casar amb Gaspar Orfanell. Va sobreviure fra Orfanell i el 1633 va donar testimoni del seu fillastre, segons relata Josep Orfanell al Sumario. 
Finalment, Fra Orfanell dedicava unes paraules de record per a cadascun dels seus germans i insistia en les recomanacions i consells: «Procurad bablar en todo verdad, porque además de ser aborrecible cosa a los hombres la mentira y lo perturba todo [...] Hablad poco y errareis poco. Vidas ajenas ni de cien leguas entren en vuestra boca y si lo oyéreis, atajadlo o apartaros». Són paraules que confirmen el seu rebuig a la maledicència i a qualsevol mena de crítica.

\subsection{Carta al P. Provincial de S. Agustín de Manila des de Nagasaki: 28 de novembre de} $1617^{38}$

En el moment en què fra Orfanell va escriure al P. Provincial de S. Agustí de Manila, fra Alonso de Baraona, feia més de tres anys que al Japó s'havia promulgat el decret de persecució del cristianisme i de l'expulsió de tots els missioners. En aquest context, la carta de Jacinto Orfanell tenia com a prioritat informar-lo de la mort de fra Hernando de St. Joseph, de l'orde dels Agustins, que va morir màrtir al Japó el 1r de juny de 1617, junt amb el Vicari provincial dels dominics, fra Alonso de Navarrete.

Aunque no conozco a V.R. Padre nuestro; la ocasión que se me ofrece es tal, que aunque parezca atrevimiento, no puedo dexar de dar a V.R. el parabien, y dichosas nuevas del martyrio del Santo Fray Hernando de San Joseph; y hazer a V.R. participante del gozo que acá tenemos, en lo que bemos visto.

Els PP. Navarrete i Hernando de St. Joseph van ser els primers màrtirs dels Ordes respectius. Aquesta era una qüestió molt important per a Orfanell; primer, perquè amb el martiri haurien pogut predicar amb l'exemple, doncs tan sols natius conversos pels seus Ordes, però cap dominic, havien donat abans la vida per la fe; i en segon lloc, perquè l’Orde de Predicadors per fi tindria el seu protomàrtir al Japó:

sin dificultad ninguna se puede dezir, que se han hecho de mayor entendimiento, y penetrado más las cosas de nuestra fe los Japones con la muerte destos gloriosos mártyres, que en setenta años que se les predica. Porque aunque se ha hecho, y trabajado mucho, no ay sermón que assípersuada lo que el hombre quiere, como dar la vida por lo que se predica. [...] y dando luz a esta christiandad, animándola con su exemplo.

L'arrest i execució de dos missioners, el P. João Baptista Machado, jesuïta portuguès i el franciscà espanyol Pedro de la Asunción el 21 de maig de 1617, va provocar que a fra Alonso de Navarrete, Vicari Provincial dominic, se li desvetllessin els anhels de martiri i la determinació de morir per enfortir l'esperit dels seus fidels. Amb aquest objectiu, va

38. Sicardo, Joseph, Libro Segundo de la Christiandad del Japón y dilatada persecución que padeció. Y de los Mártyres del Orden de N.P. S. Agustín, y los demás pertenecientes a ella, Madrid, Fr. Sanz, 1698, pp. 154-156. 
exposar el seu projecte a l'únic frare agustí que hi havia al Japó, fra Hernando de San José de Ayala, i aquest va acceptar compartir la mateixa sort. Ara bé, l'elecció d'Hernando no era casual, perquè l'objectiu de Navarrete era també que les quatre religions poguessin tenir el seu màrtir. ${ }^{39}$ D'aquesta manera, tal com ho havien previst, vestits amb els hàbits dels seus Ordes, van emprendre el camí d'Ōmura. Mentre avançaven, de manera oberta i manifesta, anaven predicant i feien lectures públiques de la Guia de pecadores, fins que els van detenir i al 1r de juny van morir decapitats. ${ }^{40}$ Però aquesta recerca deliberada del martiri ${ }^{41}$ va ser molt contestada pels jesuïtes, que veien una imprudència i una gran provocació en aquelles demostracions que, a més, es produïen pocs mesos després que l'octubre de 1616 Tokugawa Hidetada hagués promulgat un nou decret anticristià refermant les mesures que el 1614 havia dictat Tokugawa Ieyasu. ${ }^{42}$

Fra Orfanell continuava la carta explicant que també havien executat dos cristians que havien amagat els missioners a casa seva i n'havien empresonat set més: «El octubre passado fueron tambien cortadas las cabeças a los caseros de los dos santos mártyres Fray Hernando y Fray Alonso, llamados Andrés y Gaspar. Y por la misericordia de Dios están al presente siete en una cárcel de esta ciudad».

Després que uns pescadors cristians haguessin trobat una caixa amb els cossos de Fray Hernando i també el del franciscà Pedro de la Asunción, molt probablement retornada per la marea, van amagar el cos del P. Hernando, a casa d'un japonès majordom de la Confraria de la Cinta de S. Agustí en un barri de Nagasaki, ${ }^{43}$ i el preservaven com a relíquia del màrtir: «Fué en la casa, donde tienen el santo cuerpo. Está con decencia en una caxa de madera, debaxo de un altar. La causa porque no le embian, ellos la deben escribir a V.R. y el Hermano Fray Andrés». Com deia fra Orfanell a la carta, estaven a l'espera de rebre instruccions per saber on l'havien d'enviar. Continuava expressant la preocupació que tenia en ser tan pocs els missioners: «somos tan pocos Ministros, que ya no podemos con la carga. V.R. no se olvide a su tiempo de embiar también ayuda, para llevar adelante lo también començado.» Per acabar, feia una lloança de les qualitats de Fray Hernando i manifestant l'afecte que es tenien.

39. Si bé l'any 1587, al Japó es va promulgar el primer Edicte d'expulsió dels jesuïtes, els primers màrtirs no van ser de la Companyia, sinó sis franciscans que, a conseqüència dels fets desencadenats pel naufragi del galió San Felipe, el 5 de febrer de 1597 van ser crucificats junt amb vint persones més.

40. Boxer, C. R. i J. S. Cummins, The Dominican..., cit., pp. 55-56.

41. En aquells anys es va produir un debat teològic sobre la validesa del martiri provocat de fra Alonso de Navarrete i de fra Hernando de St. Joseph Ayala, que finalment van ser beatificats l'any 1867 junt amb Jacinto Orfanell i altres màrtirs del Japó. Boxer, C. R.i J. S. Cummins, The Dominican ..., cit., pp. 28, 37, 177. Es tracta d'un debat alimentat també per la rivalitat entre jesuïtes i frares, que venia del primers martiris de franciscans de l'any 1597. Vegeu: Vega, Lope de, Triunfo de la Fee...cit., p. XXXI: «alguns jesuïtes sostenien que ja que els frares havien entrat al Japó en contra dels desitjos del Papa, com es deduïa del Motu propio de Gregori XIII, havien mort excomunicats, i no eren màrtirs de la Fe sinó de la seva propia bogeria i imprudència».

42. Boxer, C. R., The Christian century in Japan 1549-1650, Berkeley and Los Angeles, University of California Press, 1967, p. 332.

43. Delgado, José, Beato Jacinto..., cit., 1983, p. 378. 
Havien passat deu anys des d'aquella primera carta que el 1609 fra Orfanell havia adreçat al prior del Convent de Santa Caterina i és possible que durant aquest període no els n'hagués escrit cap altra. Potser per això, Jacinto Orfanell la començava referint-se als remordiments de no escriure, encara que de seguida deixava clar quin era el veritable motiu de la carta: explicar-los les dificultats amb què es trobaven per dur a terme la tasca missionera, a causa de la cruel persecució del cristianisme, i proposar-los que anessin al Japó per ser ministres de l'Evangeli.

Orfanell era conscient del molt descoratjadora que podia ser la informació que devia haver arribat al convent sobre l'edicte de prohibició del cristianisme, promulgat pel govern Tokugawa el gener del 1614, i les conseqüències de l'incompliment del decret d'expulsió per part d'alguns missioners. Per això, els demanava que:

no den crédito a algunos que se buelven, que con su poco espíritu dicen abi lo que no devieran. Bien confiesso que en algunas partes de las Índias ay trabajos, pero la Provincia de Philipinas, sobre mí, que es cosa del cielo, a la qual pertenece ésto de Japón donde yo estoi.

Així doncs, per a Orfanell, les missions a les Filipines i al Japó eren obra de Déu, «cosa del cielo», una acció de la providència divina que calia acceptar.

Fra Orfanell continuava fent patent fins a quin punt el desanimava la incertesa a l'hora d'escriure, perquè no podia saber si la carta arribaria mai a destí: «me quita la gana de escrivir ver la incertidumbre que ay de llegar esta carta en camino tan largo». ${ }^{45} \mathrm{Amb}$ tot, «confiado que el Señor la llevará», seguia endavant i explicava de manera detallada alguns dels efectes que havia tingut per als cristians l'ascens al poder del shōgun Tokugawa Hidetada, que ell qualificava de «rey cruel enemigo de la christiandad», després de la mort del seu pare Tokugawa Ieyasu el maig del 1616. En els últims anys, nombrosos cristians i també missioners havien estat decapitats i d'altres, empresonats. Explicava els martiris dels PP. Juan Baptista Tavora, fra Pedro de la Asunción, fra Hernando de S. Joseph ${ }^{46}$ i el del seu Vicari Provincial, fra Alonso de Navarrete. Cal pensar que, en el moment d'escriure, Orfanell creia que de l'orde dels dominics, a la presó hi havia els PP. Thomas del Spiritu Santo Zumarraga, Ángel Ferrer Orsucci i Juan de Sto. Domingo. El que ignorava és que el mateix dia en què escrivia la carta empresonaven també al Vicari provincial, P. Francisco Morales, i el dia abans, al P. Alonso Mena. ${ }^{47}$ Per tant, ara ja tan sols quedaven tres dominics en llibertat, els PP. Juan de Rueda, Joseph de S. Jacinto Salvanés i ell mateix.

44. UB-R, Ms. 1008-1010, vol. II, f. 252-253.

45. Aquesta inseguretat es devia no tan sols pel llarg camí que havien de fer les cartes, sinó també per la freqüència dels naufragis.

46. A la carta, per dues vegades l'anomena com Fernando de S. Joseph.

47. Manzano de Haro, Melchor, Historia del insigne y excelente martirio, Madrid, Andrés de Parra, 1629, p. 44. 
Enmig aquest context, en la seva carta, Orfanell descrivia les condicions tan precàries en què escrivia:

Ase levantado una cruel persecución más que la ordinaria contra la christiandad, de tres meses a esta parte, la qual començó por essos Padres, y a los demás ha sido forçoso yrse cada uno por su parte y esconderse donde a podido; y assí yo, al presente, escrivo ésta escondido en un monte donde estoi hasta ver en qué para ésto.

A més, detallava els extrems a què havia arribat aquesta persecució, amb pregons públics i ordres com els següents:

que ninguno sea osado de dar casa, ni acoger a ningún Padre ni religioso, so pena de quemar vivos al que se les diere con muger y hijos, y a otros muchos de la calle. Ítem que dará (no me acuerdo que cantidad de plata) al que les descubriere algún ladrón, o algún Padre, o religioso. ${ }^{48}$

Per tot això, Orfanell, encara que menystenia aquelles mesures i que afirmés: «es cosa de risa, es contra stimulum calcitrare, antes es echar azeite al fuego y llamar más religiosos», en creure que podien ser un estímul per als ànims dels creients, actuava en conseqüència en sentir-se molt responsable de com pogués afectar els qui els ajudaven:

Vamos a sus casas, que es para alabar a Dios. Pero buýmos desso por no ser ocasión de que maten media calle por nuestro respecto. Y essa es la principal causa de querer yo estar escondido en este monte que si me cogen, cogeránme solo con mi ayudador de missa.

En aquest sentit, la situació havia empitjorat perquè ja no tan sols es decapitaven els sentenciats, sinó que a tot aquell que acollia un sacerdot, ara el cremaven viu. Fra Orfanell explicava que recentment havien cremat tres cristians japonesos que feia quatre anys que havien contribuït al retorn d'alguns dels expulsats pel decret del 1614, entre els quals ell mateix: «ellos de secreto desembarcaron algunos, de los quales fuý uno yo, y agora como digo, les quemaron vivos a los tres, con sus mugeres y hijos, que todos fueron doce». A més a més, s'havien introduït turments nous, que Orfanell titllava de «exquisitos tormentos» $\mathrm{i}$ els detallava: «cortados los dedos de manos y pies y las narizes, y echa una cruz en la frente con un hierro ardiente, y cortados los nervios con que jugamos la pierna tras la rodilla».

S'adreçava al Convent dient-los que possiblement els havien arribat algunes Relacio$n e s^{49}$ però que potser moltes eren d'oïdes, a diferència de les seves, sempre rigoroses i fruit de l'experiència personal:

48. També segons Manzano de Haro, Melchor, Historia del insigne..., cit., p. 43, hi havia cartells de l'Emperador i de governadors que «prometían treinta barras de plata de a quarenta reales cada una, al que descubriesse, y manifestasse algun religioso, o persona que le aposentasse».

49. Les Relaciones, en el cas de les elaborades pels missioners, eren compendis en forma de relat de fets relatius a la tasca missionera, succeïts dins un període de temps, i que sovint detallaven persecucions i martiris. 
yo todo ésto que digo es de vista, o a lo menos que me hallé bien cerca. Porque ha 12 años que estoi en Japón sin aver salido dél, ni desseo tampoco salir, sino es que la obediencia ordenasse otra cosa.

A continuació, Fra Orfanell refermava el seu compromís missioner i reclamava que ningú dissuadís aquells que volguessin anar al Japó per compartir-lo, aixó sí: «El que no se hallare con espiritu y ánimo de venir, no digo que venga, pero no estorbe al que Dios llamare». Il-lustrant la necessitat de nous religiosos, feia un recompte dels missioners actius que hi havia al Japó quan el 1619 escrivia la carta. Deixant de banda els empresonats, eren: tres franciscans, dos agustins, catorze o quinze de la Companyia i cinc dominics; encara que ell no sabia que dos més dels seus feia poc que havien estat empresonats. ${ }^{50}$ Per tant, com a màxim eren un total de vint-i-tres religiosos en llibertat:

y todos ya muy cansados y enfermos, y ninguno con desseo de salir de aqui, sino de acabar la vida en esta obediencia trabajando con nuestro pobre cornalejo, y esperando si de camino nos cupiesse alguna buena suerte, con que rematassemos cuentas, y rompiessemos papeles.

Aquell 1619, el beat ja manifestava cansament i la fatiga que retrobarem en una de les Relaciones que va escriure l'any següent. ${ }^{51}$ A la carta, hi descrivia la senzillesa de les seves condicions de vida, que no haurien d'espantar aquells que de veritat desitgessin «sacrificarse al Señor, y padecer por su amor», perquè «como dize el Padre fray Luis de Granada: gente resuelta y animosa en el servicio de Dios es la que es menester». I continuava:

porque en esta província no ay depósitos, ni en 13 años que ha que estoi en ella no be tenido en mi poder, ni en comunidad una blanca. Pero ella acude a todos con toda puntualidad en el regalo, y todo lo que es menester. En salud, dentro ni fuera del convento no se come carne; pero aviendo necessidad, con much a $c<b>$ aridad, se acude. Vestir camisa, aunque se muera no le dispensarán. Todos los dias ay dos horas de oración mental, una a media noche, otra a prima noche. Ésto ay, y hablo claro, no diga nadie después que le engañaron. En lo demás ay mucha hermandad y llaneza: todos nos tratamos de Reverencias, hasta el mismo Provincial le llamamos Reverencia.

Insistia en què no havien de creure tot el que els diguessin sobre el Japó, perquè ell mateix havia estat a punt de no anar-hi: «Yo confiesso que estuve bien apique de no salir de España, ni venir acá por essas cosas que oýa». Per això, perquè al Convent poguessin conèixer quina era la realitat, li demanava al Pare prior:

de hazer leer esta carta en comunidad, para que todos sepan lo que por acá passa, y encomienden a Dios esta tan perseguida christiandad, a la qual sinco años ba le quitaron y desterraron los mi-

50. Els PP. Morales i Mena.

51. Delgado, José, Beato Jacinto..., cit., 1984, p. 103. 
nistros, y assí los que nos quedamos escondidos hemos andado todo este tiempo a sombra de tejados, ayudándola como hemos podido.

Per acabar, en aquest mateix darrer paràgraf, Orfanell explicava que, al Japó, del Rei en deien Emperador, que tenia molts reyezuelos que depenien d'ell, als quals Orfanell tractava de «reis», ${ }^{52}$ i ho aclaria perquè ningú no es confongués quan es referia al Regne d'Arima o al Regne de Bungo que, en realitat, deia, eren com províncies. Afegia també que després de la destrucció de totes les esglésies a causa de la persecució, els temples budistes ho dominaven tot, i dels bonzos i dels ídols que adoraven en parlava de manera despectiva:

y assi las que agora ay todas son de ídolos y demonios [...] que el demonio es como mona; éstos aunque tienen diversas sectas, todos convienen en adorar a uno de dos dioses: unos adoran a Amida, otros a Xaca. Y son muy observantes y penitentes en el exterior, que allá dentro mil vellaquerias y torpezas, que aqui no se pueden dezir ni nombrar, bazen, como nos lo cuentan algunos de los mismos bonzos que se convierten a nuestra santa fe.

Per aquesta raó, demanava que al Convent preguessin: «al Señor que sea servido de destruir estos ídolos y demonios, y abrir los ojos a esta ciega y engañada gentilidad para que conosca la verdad de nuestra santa fe».

\subsection{Carta al P. Provincial Fray Melchor Manzano: 21 de març de 1621}

El manuscrit autògraf d'aquesta carta es conserva a la sagristia de l'església parroquial de La Jana, el poble natal del beat. Jacinto Orfanell s'adreçava al seu Provincial: «Aý va la relación que V.R. me mandó. Plegue a Dios que llegue en ella y en las demás que irán de los Padres. Verá V.R. lo que por acá ay y assí no cansaré a V.R. en repetirlo».

La Relación que l'acompanyava, en realitat, eren els capítols que el dominic havia redactat de la que acabaria sent la Historia Eclesiástica de los Sucessos de la Christiandad del Iapón. El capítol LX és el darrer que va escriure fra Orfanell, i l'havia completat el 17 març de 1621. Per tant, escrivia la carta a fra Melchor Manzano quatre dies després d'haver acabat la redacció de la Relación, que el Provincial li havia encomanat. ${ }^{53}$

Fra Diego Collado, a finals de novembre del 1622, després de l'anomenat Gran martiri de Nagasaki en què Jacinto Orfanell havia mort, va marxar del Japó camí cap a Roma. Gràcies a la carta que fra Joseph Orfanell va escriure l'any 1627 a Gaspar Vicenç del

52. Orfanell es referia als daimyō o senyors feudals.

53. Sense el «Suplemento Adicional a la misma Historia» amb què Diego Collado completaria l'obra per ser publicada el 1633. Tal com s'explica al pròleg de la Historia Eclesiastica, l'escrit d'Orfanell va ser revisat per més de trenta religiosos que estaven empresonats a la presó d’Ōmura. I també segons Delgado, José, Beato Jacinto..., cit., 1984, p. 106. 
Convent de Santa Catharina a Barcelona, ${ }^{54}$ sabem que Fra Diego Collado li va lliurar el manuscrit original al seu germà franciscà. ${ }^{55}$

Després d'agrair que els haguessin enviat més religiosos de reforç a la missió, fra Orfanell explicava que:

Los padres fray Luis Flores y fray Pedro de Çuñiga todavia están en poder de los herejes. Dos emos ido a ver si les pudiéramos hurtar y no a avido remedio y agora más que nunca los tienen apretados porque an dicho al emperador que son padres y está agora el pleyto entre ellos y el capitán del navio. No sabemos en qué parará.

En els primers mesos de l'any 1620, el dominic flamenc, fray Luís Flores, junt amb el frare agustí Pedro de Zuñiga, havien sortit de Manila amb destí al Japó. Viatjaven en un vaixell capitanejat pel cristià japonès Hirayama Jōchin, amb tripulació japonesa i espanyola i passatgers a bord. ${ }^{56}$ En el camí, el 22 de juliol de 1620, el vaixell va ser interceptat per una nau anglesa, i tant el capità, la tripulació, com els dos frares — que, vestits com a laics, en aquell moment negaven la seva condició-, van ser lliurats a un altre vaixell de la flota holandesa. Finalment, el 4 d'agost arribaven a Hirado i malgrat les tortures a què els van sotmetre en sospitar que eren missioners, ells no ho van admetre. ${ }^{57}$ En canvi, d'acord amb el relat de Knauth, després de molts interrogatoris, de la denúncia de Tomás Araki, apòstata japonès, $i$ de ser reconeguts per un portuguès $i$ un filipí, van acabar confessant $i$, per tant, van passar a ser competència de la justícia shogunal. ${ }^{58}$ Es van fer diversos intents de rescat, com fra Orfanell explicava a la carta. Així mateix, fra Joseph de San Jacintho, Vicari Provincial dels dominics al Japó, va donar instruccions perquè es fes tot el possible per alliberar-los del captiveri. Tanmateix, no ho van aconseguir. ${ }^{59}$

Segons el relat de Diego Collado, ${ }^{60}$ a finals d'abril de 1621, camí cap a Nagasaki, fra Orfanell predicava i administrava els sagraments pels poblets i es va aturar durant dos o tres dies a Yagami. Casualment, a la casa on era hi van arribar tres homes que creien que s'hi amagava un Pare de la Companyia, és a dir, un jesuïta. Amb tot, ben aviat es van

54. UB-R, Ms. 1008-1010. vol. II, f. 245. «El Padre fray Diego Collado (que se balló presente al martyrio de nuestros Santos) traxo de allá una larga y copiosa Relación compuesta por mi hermano, que contenía todo lo sucedido en Japón desde el dia que entró la Orden de Predicadores hasta el en que murió el santo por la fe. Y este original está en mi poder. [...] También tengo en mi poder la Relación que se imprimió en Manila el año 1622.»

55. Delgado, José, Beato Jacinto..., cit., 1984, p. 106, dedueix que apreciant com apreciava a Jacinto Orfanell, que havia estat el seu mestre de llengua japonesa, amic i colllaborador íntim, el P. Collado va voler deixar a la família també com a relíquia, l'original de la carta, que vam poder veure a La Jana.

56. Massarella, Derek, A world elsewhere: Europe's encounter with Japan in the sixteenth and seventeenth centuries, New Haven and London, Yale UP, 1990, p. 275.

57. Cabezas García, Antonio, El siglo Ibérico del Japón. La presencia Hispano-Portuguesa en Japón (15431643), Valladolid, Universidad de Valladolid, 2012, pp. 472-473.

58. Knauth, Lothar, Confrontación transpacífica: el Japón y el nuevo mundo bispánico, 1542-1639, México, UNAM, Instituto de Investigaciones Históricas, 1972, p. 287.

59. Orfanel, Jacinto y Diego Collado, Historia eclesiástica ..., cit., f. 152-155.

60. Ibidem, f. $121 \mathrm{v}$. 
adonar que el qui buscaven no hi era, però sí un altre sacerdot. Fra Collado pensava que fra Orfanell potser hauria pogut fugir, però el cas és que no ho va fer. ${ }^{61}$ Així, sense que oferís cap resistència, el van fer presoner i se'l van endur a Nagasaki, i a l'endemà a la presó de Vomura, en un vaixell que sortia de Nagaye.

\subsection{Carta al P. Fray Francisco Hurtado: 20 d'agost de $1621^{62}$}

Es tracta d'un text formal, escrit des de la presó per acompanyar la Historia Eclesiástica revisada, després d'haver fet algunes esmenes respecte als continguts de la Relación de estas cosas suçedidas en esta persecución de Japón ${ }^{63}$ que ja havia tramès al P. Hurtado l'any 1619.

\subsection{Carta a fra Joseph Orfanell: 21 de setembre de $1621^{64}$}

Des de la presó de Vomura, Jacinto Orfanell va escriure al seu germà franciscà Joseph Orfanell, i quan aquest va incloure la carta al Sumario sobre la vida del beat, s'estranyava de què li hagués pogut arribar a les mans.

Quan fra Orfanell la va escriure, al setembre de 1621, li feia saber al seu germà franciscà que acabava de rebre una carta seva de data 25 de març de 1618, i el bé que li havien fet les notícies que li donava: «con la qual por aver llegado, a tal punto me consolé mucho por saber nuevas de V.R. y de los demás parientes y conocidos». Li explicava que feia cinc mesos que era a la presó amb onze sacerdots més, franciscans, de la Companyia, sis dominics, algun clergue i molts japonesos. Un total de trenta cristians empresonats, entre els quals n'hi havia alguns que hi eren des de feia tres o quatre anys.

També va voler compartir amb ell la rudesa de la vida a la presó:

muy rigurosa y estrecha, y la comida tal que me espanto como no se mueren algunos. Pero no la trocáramos por todas las delícias y regalos del mundo; ni esta estrechura por los anchos palacios de los reyes y monarcas de la tierra, por ser por tan buen Señor a quién rogamos no nos saque de aqui sino para dar la vida por su santo nombre.

Fra Orfanell, en aquells dies pensava que aviat els traurien per executar-los i, si li escrivia al seu germà, era perquè volia que ho sabessin, tant ell com la seva mare, en el cas

61. Ibidem, f. 122: «dexándose llevar más a mi parecer del gran deseo que tenía de ser preso, y muerto por Christo nuestro Señor, como avía mostrado en muchas ocasiones, hasta llegar una vez (viéndole enfermo, y cansado de trabajar, y impossibilitado a su parecer para encubrirse en tiempo de persecución, por ser muy conocido en Iapón, aún de los Gentiles, desde el tiempo de las iglesias, y muy alto de cuerpo, y diferente en phinosomía de los Iapones) a quererse presentar a los juezes para assegurar su salvación».

62. Ibidem, Prólogo.

63. Delgado, José, Beato Jacinto..., cit., 1984, pp. 41-88.

64. UB-R, Ms. 1008-1010, vol. II, f. 245-245v. 
que fos viva, ${ }^{65}$ però també altres parents i coneguts. Ho feia tot expressant de nou la incertesa sobre si la carta arribaria a destí:

estos ringlones, aunque yrán muy a la ventura; porque aunque e podido escrivir, no sé si podré entregar la carta, porque son tantas las guardas, que ningún christiano se osa llegar. Y la de V.R. fué gran ventura entrar anoche, porque se animó un buen christiano, porque llovía, y los guardas estavan descuidados, y la metió. Pero allá va a la ventura.

El dominic li explicava que tenia notícies que a les presons públiques de la ciutat de Nagasaki hi havia cristians empresonats per haver acollit a casa seva alguns dels religiosos que eren a la presó, i li semblava que els havien de cremar vius. Pel que feia a ells, se sincerava dient-li que creia que els executarien en secret per temor que el martiri fos motiu de concentració de molts cristians. Li explicava també que l'any anterior hi havia hagut molts màrtirs, entre els quals alguns sacerdots dels diferents ordes, i que tot plegat ho havia explicat en diverses Relaciones. «Y porque estoi de prissa, no más». I acabava la carta —inclosa a l'Apèndix documental— dient: «que nuestro Señor [...] nos junte en el cielo».

\subsection{Carta a fra Diego Collado: 25 d'agost de $1622^{66}$}

«Al Señor Salmantino guarde Nuestro Señor». Així és com fra Orfanell s'adreçava a fra Diego Collado i en una nota al marge fra Gaspar Vicenç aclaria: «llama Salmantino al Padre fray Diego Collado su Vicario general, y en la carta le llama nuestro amo por dissimular, $y$ le trata de V.M.» Això és degut a que, com fa notar Boxer, ${ }^{67}$ per raons de seguretat, a vegades recorrien a paraules «codi». Per exemple, d'un sacerdot en podien dir «doctor», dels estris per dir missa, «medicina»; i en el cas dels superiors de l'Orde, solien adreçars'hi com «Capitán» o, com veiem que feia Orfanell, que anomenava Collado «Señor Salmantino». De la mateixa manera, i també ho comprovem a la carta, en lloc d'utilitzar la forma «Vuestra Reverencia», feia servir «Vuestra Merced». Aquesta estratègia era, d'altra banda, força innocent perquè el text, en aquest cas, era prou explícit amb les referències a «Jesu Christi», «lo pagarán desde el cielo», «el Señor», «la Fe» o la «Santa Iglesia Romana».

Quan fra Orfanell va escriure aquesta carta sembla que hi havia indicis que s'acostava el dia del martiri: «que nos han doblado las guardas, las quales de noche y de dia están con

65. Càndida Boix va morir l'any 1633.

66. UB-R, Ms. 1008-1010, vol. II, f. 125. Les cartes que el P. Gaspar Vicenç va copiar i va incloure en un recull, junt amb la de Jacinto Orfanell, són dels dominics Pedro Vázquez, José de San Jacinto, Alonso de Mena, Francisco Morales i Nagixi Pablo, i anaven adreçades a Diego Collado, Juan de los Angeles i a Diego de Rivavelloso, tots del mateix Orde. Van ser escrites des de diverses ciutats del Japó, entre el 12 de març de 1621 fins al 10 d'octubre de 1623. Com a introducció, el P. Vicenç hi explicava que ell mateix les havia copiades dels manuscrits originals, aprofitant que les portava fra Diego Collado quan havia passat per Barcelona camí cap a Roma. Aquesta carta també es troba reproduïda dins del Sumario de Joseph Orfanell i a la Historia eclesiástica..., cit., f. $118 \mathrm{v}$.

67. Boxer, C. R. i J. S. Cummins, The Dominican..., cit., p. 50. 
gran vigilancia, y assi de hora en hora estamos esperando el dichoso plazo». Fa l'efecte que li volia confirmar a Collado la seva fermesa, que no defalliria, perquè afegia: «esté V.M. cierto que no seré como el Copero de Faraón», per continuar més endavant amb allò que sabia, dins la incertesa del final:

No nos dezían las nuevas, la muerte que nos ban de dar, si de cruz, fuego, cuchillo, etc., pero sea la que fuere, y el demonio pudiere inventar, estamos muy aparejados con el ayuda del Señor a padecerlo todo.

També li agraïa que hagués tingut cura de les persones que l'acollien a casa seva quan el van detenir, com Matias Matayemon, «y doy muchas gracias de como an acudido al consuelo de nuestro casero». I és que, com explicava fra Diego Collado, ${ }^{68}$ quan van capturar fra Orfanell, també van detenir les cinc persones que vivien a la casa, i ell mateix els havia anat a veure a la presó per consolar-los i confessar-los.

Aquesta és la darrera carta que ens consta que va escriure fra Jacinto Orfanell, inclosa a l'Apèndix documental. L'acabava amb una expressió de gran afecte per fra Diego Collado: «mi charíssimo compañero y Padre». El martiri de fra Orfanell seria setze dies més tard, el 10 de setembre de 1622.

\section{Relaciones ${ }^{69}$}

Tant les Relaciones com bona part de les cartes que van escriure els missioners dominics des del Japó, responien a la sistematització en l'enviament de reports que el General de l'Orde havia exigit de manera formal perquè, sota pena de pecat mortal, calia que enviessin un informe anual sobre el progrés de la missió. ${ }^{70}$ En el cas de fra Orfanell, veiem que va complir el mandat perquè a més de cartes, de Relaciones — que es conegui-, en va escriure quatre, algunes d'elles anticipant la seva obra més coneguda, la Historia Eclesiástica.

\subsection{8 de març de 1615: Breve Relación de los Mártyres de Japón para el Padre Fray Balthasar Fort. Persecución de Arima, Ariye y Cuchinots ${ }^{71}$}

El dominic P. Baltasar Fort, el 1612, havia estat nomenat In Vicarium Nationis del Japó i el 6 de novembre de 1614 va ser un dels missioners que es van embarcar de retorn a Ma-

68. Orfanel, Jacinto y Diego Collado, Historia eclesiástica..., cit., f. 125.

69. Com que no ha estat possible accedir als manuscrits originals de les quatre Relaciones obra de fra Jacinto Orfanell, que es conserven a l'APDA, per fer la ressenya hem utilitzat les transcripcions fetes per Delgado, José, Beato Jacinto..., cit., 1983-1984, qui sí que hi va tenir accés.

70. Vega, Lope de, Triunfo de la Fee en los reynos del Japon, J. S. Cummins (ed.), Londres, Tamesis Books Limited, 1965, p. XXXIII.

71. La revista Misiones Dominicanas, una publicació que el Colegio de Santo Tomás d’Àvila va editar en- 
nila a causa del decret d'expulsió. ${ }^{72}$ En aquest escrit, fra Orfanell relatava els fets més rellevants ocorreguts d'ençà que el P. Fort havia marxat. Al final d'una extensa relació de persecucions i martiris, Jacinto Orfanell inclö̈a un darrer paràgraf pel qual donava instruccions per a l'enviament del document a Espanya:

Otro traslado [Ca] también para V.R. deste borrador, en el qual de propósito hago mención de los mártyres de los años pasados, con intento de que senbiasse a nuestra provincia ${ }^{73}$ o, la sustançia dél para que sepan de las maravillas que el Señor obra por acá. Pero después de escrito me dixeron que V.R. no estará en Manila quando estas cartas lleguen, y assí remitto el traslado al Padre prior de Manila para que le enbien a España, y lo que V.R. dessea saber en sustançia aquí va todo. ${ }^{74}$

Un dels aspectes més rellevants d'aquesta Relación és que el document que anomena «traslado» és el que va arribar a mans de Lope de Vega, poeta i dramaturg espanyol, el qual el va utilitzar per escriure el Triunfo de la Fee en los reynos de Japón por los años de 1614 y 1615. ${ }^{75}$ Si seguim el que explica Boxer, ${ }^{76}$ el context que ho va afavorir va ser que en aquells anys hi havia la necessitat de defensar el protomàrtir dels dominics Alonso Navarrete, a qui els jesuïtes titllaven d'imprudent i acusaven de ser a l'origen de l'esclat de la persecució dels missioners al Japó.

Lope de Vega assegurava que les fonts per a la seva obra provenien del Japó i de Filipines i en una carta que escrivia el 1617 al duc de Sessa afirmava: «Mi estudio estos dias ha sido una bistoria de unos mártires, o digamos Relación, a que me ha obligado haberme escrito unos Padres desde el Japón». Del que no hi ha dubte és de l'autoria de la Relación que va arribar a Lope de Vega, i tampoc que va ser la seva font principal per escriure l'obra. Per demostrar-ho, Cummins acara la Relación de fra Orfanell amb els textos del Triunfo de la Fee. Amb tot, és curiós que Lope de Vega no identifiqués mai Jacinto Orfanell com la seva font, encara que sí que el va anomenar com un dels missioners al Japó, quan descrivia la persecució a la ciutat d'Arima: «Entre los que con mayor ánimo emprendieron este consuelo fue el padre fray Jacinto Orfanel, dominico, de la provincia de Aragón». ${ }^{77}$

tre els anys 1919 i 1925 va publicar aquesta Relación a la secció anomenada «Epistolario de nuestros mártires» a partir de la transcripció que es conserva a l'APDA: (APSR, Sección, 10-11, Documentación diversa, Tomo 020, Sección Japón, Tomo 10, Copia a maquinilla de las cartas de nuestros mártires en el siglo XVII). Aquesta transcripció, segons citen, va ser la font de Boxer, C. R. i J. S. Cummins, The Dominican ..., cit.

72. Delgado, José, Beato Jacinto..., cit., 1983, p. 355.

73. Ibidem, p. 375. Balthasar Fort i Orfanell pertanyien a la Província d’Aragó.

74. Ibidem, p. 375.

75. Vega, Lope de, Triunfo de la Fee...cit.

76. Boxer, C. R. i J. S. Cummins, The Dominican..., cit., p. 37.

77. Delgado, José, Beato Jacinto..., cit., 1983, p. 357, cita El triunfo de la fee de Lope de Vega. 
Segons Jose Delgado, ${ }^{78}$ el 20 d'abril de 1619, el Capítol Provincial de la Província del Santo Rosario va encarregar als PP. Francisco Morales i Alonso de Mena que redactessin la història del que havia succeït al Japó fins aquelles dates, però el cas és que tots dos eren a la presó des del mes de març i per això el P. Francisco Hurtado va encomanar a Jacinto Orfanell aquella tasca.

Un dels aspectes més destacables d'aquesta Relación és que recull les dades bàsiques dels fets ocorreguts relatius a l'evangelització del Japó, als quals més endavant fra Orfanell donaria forma definitiva i fra Diego Collado completaria per arribar a ser la Historia Eclesiástica. Si bé començava el relat amb la data d'inici de la persecució al 1614, Orfanell de seguida va recular fins el 1609 per poder parlar d'allò que ell personalment havia vist o conegut de molt a prop i acabar l'any 1619.

Fra Orfanell des d'un dels primers paràgrafs va mostrar el seu capteniment, sempre reservat i humil, i hi expressava fins a quin punt l'incomodava parlar d'ell mateix:

Y por esta razón, como digo, apuntaré aqui todos los que se me acuerdare que bien sé que se me olvidan algunos. Ase de offreçer en este papel hablar muchas vezes de mí (porque de los otros padres cada uno dirá lo que le a suçedido que lo sabrá major) $Y$ assi será necessario arrimar por un rato el encojimiento para poder hablar claro, aunque sea todo poquedad, pues lo manda obediencia [...] Y assi amore Dei no se offenda V.R., mi Padre Fray Francisco, viéndome contar mis cosas. ${ }^{79}$

\subsection{0 de març de 1620: Al P. Fr. Melchior de Mançano, provincial de la provincia del Santo Rosario de Philipinas}

Fra Orfanell va escriure aquesta nova Relación adreçada al P. Provincial, tan sols uns mesos més tard que la que havia enviat al P. Hurtado, i el punt de partida és el final d'aquella. Per això és més breu i comença amb fets a partir de l'octubre de 1619.

De nou aprofitava per demanar que enviessin més religiosos «y que comiençen aý a aprender lengua, porque aqui no les á de quedar maestro». Alhora, la petició de mitja dotzena de túniques «que tenemos much a falta; a lo menos yo, todas las tengo bechas pedaços» és un reflex de la precarietat amb què vivien. D'altra banda, creiem que l'aspecte més significatiu i destacable d'aquesta Relación és la confessió de fra Orfanell al seu Provincial sobre les dificultats amb què els dominics es trobaven en la relació amb la Companyia de Jesús i, sobretot, la seva preocupació perquè els jesuïtes poguessin estar preparant un nou Breu papal que posés límits territorials a l'acció missionera dels dominics al Japó. ${ }^{80}$

78. Delgado, José, Beato Jacinto..., cit., 1984, pp. 41-42.

79. Ibidem, p. 43.

80. Malgrat el valor documental d'aquest fragment, relatiu a l'actuació dels jesuïtes, hem pogut comprovar que, a la transcripció feta l'any 1923 que es conserva a l'APDA (APSR, Sección Japón, 10-11, Documentación diversa, Tomo 020, Sección Japón, Tomo 10, Copia a maquinilla de las cartas de nuestros mártires en el si- 
Els qui el van conèixer, de manera reiterada, remarcaven la discreció habitual de Jacinto Orfanell, els seus silencis i la incomoditat que li provocava el blasme als altres. ${ }^{81}$ Per tant, tot i ser una crítica molt continguda, com es pot comprovar en el fragment que incloem a l'Apèndix documental, les paraules de preocupació que fra Orfanell adreça al P. Manzano sobre l'actuació dels jesuïtes, pel fet de contrastar amb el seu tarannà habitual, creiem que encara tenen més valor.

En el paràgraf de comiat, fra Orfanell, de manera emotiva feia la que creiem que és una de les seves manifestacions més íntimes, sinceres i colpidores: «suplico no se olvide de este miserable en sus sanctos sacrifícios y oraciones, que ya no me conocerá si me ve. Viejo, cansado, lleno de canas y de pecados».

\subsection{Any 1620: Relación de cosas de Japón para el P. Fr. Francisco Hurtado}

Segons explica el P. Delgado, ${ }^{82}$ tant pel format com pel contingut, aquesta darrera Relación té com a objectiu respondre unes preguntes que sembla que el P. Hurtado havia formulat a fra Orfanell, en relació a unes dades sobre el Japó anteriors al 1602, que va ser l'any d'arribada dels dominics.

\section{Conclusions}

Les cartes de fra Jacinto Orfanell han estat la nostra font principal i la seva lectura crítica, junt amb la interpretació dels textos i de les petites narratives que contenen, ens han estat útils per apropar-nos al coneixement del contacte cultural que es va establir entre dos mons tan diversos com eren el Japó de principis del segle XVII i la mentalitat evangelitzadora hispano-portuguesa, representada aquí per fra Orfanell i els dominics, però alhora compartida pels missioners de les quatre «religions» que aspiraven a propagar la seva fe.

La capacitat d'observació de fra Orfanell i el rigor que se li reconeix a l'hora d'exposar els fets: «yo todo ésto que digo es de vista, o a lo menos que me ballé bien cerca»,

glo XVII), s'hi havien eliminat els quatre paràgrafs que contenen la crítica que feia fra Orfanell. I també que aquesta transcripció incompleta de la Relación es la que es va publicar a la revista Misiones Dominicanas. Per tant, si l'hem pogut conèixer, ha estat gràcies a Delgado, José, Beato Jacinto..., cit., 1984, pp. 94-103, que la va transcriure a partir del manuscrit original.

81. Fra Diego Collado va escriure sobre fra Orfanell a: Orfanel, Jacinto y Diego Collado, Historia eclesiástica..., cit., Pròleg: «por ser el dicho Padre muy modesto, verdadero, docto y escrupuloso [...] y lo que sabe de otras Religiones que sea en su abono, lo dize todo con espíritu, lenguaje y ánimo llano, verdadero, uniforme, y sin emulaciones, y aún en algunas cosas que parece que tocan en alguna manera el descrédito de algunas personas, en particular religiosas (que no pudo escusar el tocarlas) o lo haze con mucha brevedad, y de passo, o los escusa dorando intenciones, sin nombrar personas, ni aún de que religión eran, siendo cosa bien pública en Iapón, y otras (que quizás importara escrivirse para que se supiesse la verdad con que algunos redimieran su bexación, y otros escarmentaran en cabeça agena) no las quiso escribir, diziendo que solo escrivía para edificación».

82. Delgado, José, Beato Jacinto..., cit., 1984, p. 89. 
afegeix valor al seu testimoni. D'altra banda, Jacinto Orfanell, format en teologia, davant les diverses veritats de les sectes budistes que predicaven els bonzos, jutjava i valorava els monjos pel seu curós aspecte extern però els demonitzava per les pràctiques i pels ídols que adoraven, sense que ni a les seves cartes ni als escrits hi hàgim pogut veure cap evidència d'un intent d'aproximació o de curiositat intel-lectual per aquelles pràctiques $\mathrm{i}$ creences tan distants de les seves. De manera que, el que creiem que també reflecteix el testimoni d'Orfanell, és que el desinterès per arribar a conèixer o mirar de comprendre el budisme va contribuir al fet què no fos possible construir un horitzó compartit i a què l'autèntica trobada cultural fos inexistent. En canvi, aquesta trobada, amb matisos i parcialment, sí que es va donar, per exemple, en el cas dels jesuïtes. Ho veiem en Francesc Xavier, S. J., des de la seva arribada al Japó (1549-1551); ${ }^{83}$ però l'interès pels déus i les sectes del Japó ja es manifesta en l'informe del Superior de la missió jesuïta, Cosme de Torres (1510-1570), de l'any 1551, quan descrivia els monjos de la secta Zen com a «grans meditadors».84 Tot i això, qui va mirar d'intensificar l'acomodació, entre els anys 1574 i 1606, va ser el Visitador de la Companyia de Jesús, Alessandro Valignano (1539-1606), decidit a què l'evangelització es realitzés a través de la cultura. ${ }^{85}$ Tanmateix, com afirma Joan Pau Rubiés, ${ }^{86}$ si bé en la trobada dels jesuïtes amb el Japó es van crear les bases per a una espècie de «diàleg cultural» —entenent-lo com a converses per aprendre on eren les diferències - es podria concloure que el diàleg religiós real era, sobretot, sobre la recerca d'un terreny comú per al desacord.

Fra Orfanell, des que va arribar al Japó, es va preocupar per aprendre la llengua, un coneixement que, per ser indispensable, cap dels missioners no es qüestionava. Al Japó, va viure amb coherència i fins a l'extrem la pobresa evangèlica que defensava, i que els ordes mendicants van practicar de manera inequívoca. Com els escrits també demostren, fra Orfanell va ser solidari amb els més humils i els més pobres i, segons el testimoni dels qui el van conèixer de prop — fra Collado o el seu germà franciscà, fra Joseph—, el beat era senzill i discret, humil, bondadós amb els altres i estava amarat d'un veritable zel missioner. Ara bé, el beat Orfanell era extremadament escrupolós, sense qüestionar mai l'obediència als seus superiors, estricte i molt exigent amb ell mateix, fins al punt de dis-

83. San Francisco, Javier, Cartas y escritos de San Francisco Javier, Madrid, Biblioteca de Autores Cristianos, Madrid, 1953.

84. App, Urs, The Cult of Emptiness. The Western Discovery of Buddhist Thought and the Invention of Oriental Philosophy. Rorschach, Kyoto, UniversityMedia, 2012, pp. 25 i 34. El Sumario de los errores (1556) és el primer document occidental que identifica el Shintoisme i el Budisme com a principals religions japoneses.

85. Morán, J. F., The Japanese and the Jesuits: Alessandro Valignano in Sixteenth Century, Londres, Routledge, 1993, p. 55: El 1581, Valignano escrivia Advertimentos, un manual de decòrum que es basava en el Rinzai de la secta del Budisme Zen. Vegeu també: Valignano, Alejandro, S. I. Sumario de las cosas de Japón (1583), Adiciones del Sumario de Japón (1592), Tokyo, Sophia University, 1954.

86. Rubiés, Joan-Pau, «The Concept of Cultural Dialogue and the Jesuit method of Accommodation: between Idolatry and Civilization», Archivium Historicum Societatis Iesu, vol. 74, núm. 147, 2005, pp. 237-280 $\mathrm{i}$ «Real and imaginary dialogues in the Jesuit Missión of Sixteenth-century Japan», Journal of the Economic and Social History of the Orient, vol. 55, Leiden, 2012, pp. 447-494, 449 i 492. 
ciplinar-se gairebé cada nit. Probablement, fruit de l'educació familiar que havia rebut, però també de la repressió que comportava la mentalitat religiosa de l'època, Orfanell va patir de manera permanent el turment del temor de la condemna i de no ser mereixedor de la salvació. Sempre disposat a donar la vida per la seva fe, la primera carta que va escriure al Convent de Barcelona tenia com a prioritat celebrar la mort del màrtir León Shichiemon i quan la persecució es va fer més rigorosa, a partir de l'expulsió del 1614, malgrat la plena consciència de la seva vulnerabilitat, es va preocupar abans que res dels riscos que podrien córrer els qui l'acollissin a casa seva. En aquest sentit, creiem interessant notar que, no només no va defugir cap dels perills que el podien conduir al martiri, sinó que va triar viure de manera furtiva i a la intempèrie, tot i estar malalt i sentir-se vell i cansat.

En aquells anys, en què les persecucions eren una realitat quotidiana, el martiri havia esdevingut una qüestió central. El context de fracàs i de catàstrofe, que feia que els esforços evangelitzadors fossin en va, posava en crisi de manera real les perspectives per a les conversions. En conseqüència, i arran d'aquella conjuntura, entre els religiosos els objectius de conversió es van transformar en una més forta disposició a morir i en una decidida aspiració al martiri. De la «willingness to die», en parla Gregory ${ }^{87}$ i la compara amb la d'aquells primers cristians que també van suportar unes morts terribles abans de renunciar a les seves conviccions i creences. En el cas d'Orfanell, creiem que la disposició era íntima i personal, sense pretensions exemplaritzants, almenys no com la prioritat que va empènyer fra Navarrete a buscar el martiri de manera activa per tal de guiar altres ànimes a la salvació eterna.

D'altra banda, l'enfrontament dels mendicants amb la Companyia de Jesús va contaminar les seves relacions. El dret a evangelitzar el Japó, a partir del primer Breu de Gregori XIII al 1585, promogut pels jesuïtes i pel qual se'ls concedia l'exclusiva de l'evangelització, pot ser vist a l'origen de les discrepàncies i les rivalitats que tant van enrarir la seva convivència i que, com ha estat reconegut, va contribuir al fracàs de la missió que en realitat tots compartien, fins al punt que la discreció extrema de fra Orfanell es va veure superada per la necessitat de fer partícip el Provincial dels dominics del seu neguit davant l'actuació dels jesuïtes. Van ser energies perdudes per al projecte que era comú. No obstant això, en el camí del desenllaç, en els dies de presó compartits, probablement arribaven a un punt de trobada en què les hostilitats desapareixien i junts es feien més forts per anar al martiri que desitjaven. Era una aspiració que, segons explicava fra Orfanell de manera reiterada, feia que hi anessin amb esperit de celebració.

De les despulles de molts d'aquells màrtirs se'n van fer relíquies, objectes de culte, però del beat fra Jacinto Orfanell tot el que en va quedar, més enllà de la memòria de l'obra missionera i el culte dels seus fidels, són les cartes i els escrits que ens apropen a la seva persona i a les circumstàncies del moment històric en què va viure.

87. Gregory, Brad S., Salvation at Stake. Christian Martyrdom in Early Modern Europe, Cambridge, Harvard University Press, 2001, p. 127. 


\section{Bibliografia}

\section{Fonts primàries}

Archivo Provincial Dominicos de Ávila. (APDA)

Archivo de la Provincia del Santo Rosario (APSR)

—, APDA - APSR - Sección Japón, Doc. 1-16. Relaciones, T. 013, Japón, T. 1, ff. L-482.

—, APDA - APSR - Sección Japón, T. 7. Doc. 1-6, ff. 7-23, T. 017.

—, APDA - APSR - Sección Japón, T. 7. Doc. 1-6, ff. 7-23. T. 017. ff. 30-32.

—, APDA - APSR - Secc. Japón, 10-11, Doc. diversa, T. 020, Secc. Japón T. 10. Copia a maquinilla de las cartas de nuestros mártires en el siglo XVII: pp. 84, 167, 168, 172.

Biblioteca de la Universitat de Barcelona, Reserva. Ms. 1008-1010. (UB-R)

—, UB-R. vol. I, f. 196-197v.

—, UB-R. vol. II, ff. 132-134, 109-109v, 113v-117v, 125-127v, 244v-251v, 252-253, 314-315, 315318.

Aduarte, Diego, Historia de la provincia del Sancto Rosario de la Orden de Predicadores en Philippinas, Iapón y China 1569-1636, Manila, Colegio de Sancto Thomas, Luis Beltran impresor, 1640.

Collado, Fray Diego, Señor. Fray Diego Collado de la Orden de Predicadores digo: que aunque siempre he procurado guardar toda modestia religiosa y christiana, ... me han obligado a hablar claro, Madrid, 1633.

Manzano de Haro, Melchor, Historia del insigne y excelente martyrio que diez y siete religiosos de la Prouíncia del Santo Rosario de Filipinas, padecieron en... Iapon por la predicación del Santo Euangelio, Madrid, Andres de Parra, 1629.

Ocio, P. Hilario, Compendio de la reseña biográfica de los Religiosos de la Provincia del Santísimo Rosario de Filipinas des de su fundación basta nuestros días, Manila, 1895.

Orfanel, Jacinto y Diego Collado, Historia eclesiástica de los sucessos de la christiandad de Iapon: desde el año 1602, que entró en el la Orden de Predicadores, hasta el de 1620 / compuesta por el Padre Fray Iacinto Orfanel...; y añadida hasta el fin del año de 1622 por el Padre Fray Diego Collado, Madrid, Viuda de Alonso Martín, 1633.

Sicardo, F. Joseph. Libro Segundo de la Christiandad del Japón y dilatada persecución que padeció. $Y$ de los Mártyres del Orden de N.P. S. Agustín, y los demás pertenecientes a ella... Madrid, Fr. Sanz, 1698, pp. 30-37, 41-47, 49-79, 83-90.

\section{Referències bibliogràfiques}

App, Urs, The Cult of Emptiness. The Western Discovery of Buddhist Thought and the Invention of Oriental Philosophy, Rorschach, Kyoto, UniversityMedia, 2012.

Arimura, Rie, «Las misiones católicas en Japón (1549-1639): análisis de las fuentes y tendencias historiográficas», Anales del Instituto de Investigaciones Estéticas, vol. 33, núm. 98, México, 2011, pp. 55-106.

Boxer, Charles, R. i James S. Cummins, The Dominican Mission in Japan (1602-1622) and Lope de Vega, Roma, Archivum Fratrum Praedicatorum, vol. XXXIII, 1963.

Boxer, Charles, R., The Christian century in Japan 1549-1650, Berkeley and Los Angeles, University of California Press, 1967. 
Cabezas García, Antonio, El siglo Ibérico del Japón. La presencia Hispano-Portuguesa en Japón (1543-1643), Valladolid, Universidad de Valladolid, 2012.

Delgado García, José, «Beato Jacinto Orfanell O.P., religioso de la Província dominicana de Aragón: Cartas y Relaciones», Escritos del Vedat, vol. XIII, Torrente, Facultad de Teología de San Vicente Ferrer, 1983, pp. 317-385.

—, «Beato Jacinto Orfanell O.P., religioso de la Província dominicana de Aragón: cartas y relaciones» (continuación), Escritos del Vedat, vol. XIV, Torrente, Facultad de Teología de San Vicente Ferrer, 1984, pp. 41-112.

Gargallo Valls, José, La Jana. I Centenario de la Beatificación de Jacinto Orfanell, La Jana, 1967.

Gregory, Brad S., Salvation at Stake. Christian Martyrdom in Early Modern Europe, Cambridge, Harvard University Press, 2001.

Knauth, Lothar, Confrontación transpacífica: el Japón y el nuevo mundo bispánico, 1542-1639, México, UNAM, Instituto de Investigaciones Históricas, 1972.

Massarella, Derek, A world elsewhere: Europe's encounter with Japan in the sixteenth and seventeenth centuries, New Haven and London, Yale UP, 1990.

Morán, J. F., The Japanese and the Jesuits: Alessandro Valignano in Sixteenth Century, London, Routledge, 1993.

Muñoz, Honorio, «Los dominicos españoles en Japón (siglo XVII)», Separata de Missionalia hispanica, año 22, núm. 64-65, Madrid, Raycar, 1965, pp. 53-226.

N.A., Misiones Dominicanas, vols. II-VIII, Madrid-Alcalá, 1919-1925.

Rubiés, Joan-Pau, «The Concept of Cultural Dialogue and the Jesuit method of Accommodation: between Idolatry and Civilization», Archivium Historicum Societatis Iesu, vol. 74, núm. 147, 2005, pp. 237-280.

-, «Real and imaginary dialogues in the Jesuit Mission of Sixteenth-century Japan», Journal of the Economic and Social History of the Orient, vol. 55, Leiden, 2012, pp. 447-494.

San Francisco, Javier, Cartas y escritos de San Francisco Javier, Madrid, Biblioteca de Autores Cristianos, 1953.

Tronu, Carla, «The Rivalry between the Society of Jesus and the Mendicant Orders in Early Modern Nagasaki», Agora: Journal of International Center for Regional Studies, núm. 12, 2015, pp. 25-39.

Valignano, Alejandro, S. I. Sumario de las cosas de Japón (1583), Adiciones del Sumario de Japón (1592), Tokyo, Sophia University, 1954.

Vega, Lope de, Triunfo de la Fee en los reynos del Japón, J. S. Cummins (ed.), London, Tamesis Books Limited, 1965.

\section{Apèndix documental}

20 de març de 1620: Fragment Relación. Al P. Fr. Melchior de Mançano, provincial de la província del Santo Rosario de Philipinas. ${ }^{88}$

88. Fragment de la Relación publicada a Delgado, José, Beato Jacinto..., cit., pp. 100-103, 1984 i eliminat de la transcripció APDA-APSR, Secc. Japón, 10-11, Doc. diversa, T. 020, Secc. Japón, T. 10, Copia a maquinilla..., cit. i Misiones Dominicanas. 
Para remate desta quiero avisar a V.R. de algunas pesadumbres que passamos con los Padres de la Compañía. Y son que, como su prelado es el Provisor deste obispo, ha repartido lo más del Japón entre sus religiosos, que serán poco más de veynte y assí a quién dellos cabe un reyno, a quién, dos y tres, y a algunos, más. Es verdad que en una cierta parte está muchos en un reyno, y todos ellos assí los unos como los otros, se llaman parrochos, y dizen, y con los christianos lo procuran, que no entremos a administrar sus ovejas, máxime de assiento, porque si vamos de passo, no dizen nada, a lo menos no lo muestran tanto, y si es a partes donde ellos con difficultad pueden acudir, mucho menos; pero en este reyno donde digo que ellos están muchos y tan de assiento,${ }^{89}$ no falta harto que hazer quando otro religioso passa por allí, pues de los reynos que caben a dos y tres a cada uno no ay que hablar, porque passan años que no le ven, porque si por allá está de passo o tan escondido por el tiempo que quál o quál es el que le alcança a ver y assí se queda todo iermo y con mil trabajos y desventuras, como lo é experimentado hartas veces. Y ahora acabo de venir de un reyno y no muy lexos de donde los Padres estan de assiento, donde hallé que las cabeças de los pueblos por ignorancia tenian un ierro intolerable que tocava en la Fee, en el qual avian caído por aver mucho que no vían Padre y gracias a Dios, quedó remediado.

Todo ésto digo para que sentienda que no pueden acudir Padres a todo siendo tan pocos. Ponen la Cofradía del rossario ${ }^{90}$ en todas las partes donde están, y si nosotros las queremos poner, lo procuran buenamente impedir por medio de sus dogicus y afficionados, porque vean que si fundamos la cofradía, como tiene indulgencias y la suya no, acuden los christianos también a nosotros y es ocasión de meternos en sus parrochias que ellos llaman. Aunque lo que ellos sienten no es tanto, a mi pareçer, por lo de las parrochias, como porque se meta otro en christiandad echa por ellos antiguamente, pero en este tiempo cada uno ayuda como puede.

Mucho temo que con el poco gusto que estos Padres (que alias acuden bien a su ministerio) tienen de que haya çerca de sí otros religiosos, an de procurar sacar algun bulleto, no de que no vengan las demás religiones a Japón, que esso no lo alcançarán ya, sino que dirán que pro bono paçis no entre una religión en el reyno o parte donde estuviere ya otra, y ésto sería en buen romançe sacarnos casi de todo Japón, porque pocas partes ay donde ellos no ayan tenido algo y ahora no lo tengan repartido entre sí, como tengo dicho. Es verdad que ahora tres años, siendo nuestro Vicario Provincial el sancto mártyr Fr. Alonso Navarrete, convidó el provisor por vezes y con mucha instancia a todas las religiones que tomassemos también parrochias encargándonos de algunos partidos, y me acuerdo que todos respondieron que nuestro instituto era de acudir al próxi-

89. Delgado, José, Beato Jacinto..., cit., 1984, p. 101, fa notar que fra Orfanell no especifica ni regions ni persones, però que a Roma a l'Arxiu de Propaganda Fide, vol. 99, fols. 123-148v hi ha una Relación del P. Rueda de data 04.09.1621, De una persecución particular y doméstica que bay en Japón, que sí que recull casos amb noms d'indrets i de persones.

90. Segons la mateixa Relación del P. Rueda, f. 146v, els jesuïtes volien obtenir de Roma llicència per fundar ells, i només ells, la Confraria als llocs on eren. 
mo de charidad, y assí que no queríamos obligarnos con parrochias para poder mejor acudir a todas partes. Y assí entonçes el provissor lo repartió por parrochias entre sus religiosos, y ay lo que tengo dicho. El Señor nos haga santos. Esso de apellidar diócesis y llamarse parrochos y quexarse si otros llegan a administrar sus ovejas y dezir que en esto vamos contra la voluntad del vicario del obispo, es lenguaje sólo de los Padres particulares que están repartidos, como ellos dizen; pero lo que es el provisor hasta ahora no nos a dicho nada, pero entiéndese que todo va allá con traça de todos para que no entremos donde ellos estan sacando la brasa con la mano de gato a título de parrochias. Allegan lo que passa en la India y Manila, que una religión no entra en el distrito donde está la otra, pero aquí es differente, porque, aún quando avía paz en Japón y cada religión estava y acudía en particular donde le davan los tonos iglesias sin hazer agravio a nadie procurava, cada uno entrar y alcançar licencia del tono para levantar iglesia donde otros estavan. Y ésto lo víamos cada día, v.gr. en Yendo estavan los Padres Franciscos, y después fueron allí a fundar los de la compañía. Y todos ívamos desta manera. De suerte que toda la difficultad estava en si el tono daría licencia; y assí si en tiempo de paz ívamos por este camino, quanto más justo es que vaiamos ahora, que todo es persecución, y que cada uno acuda donde pudiere, aviendo tantos reynos cuyos christianos se van de cada día bravamente enflaqueçiendo por aver muchos años que no ven sino bonzos malditos que les procuran atraher a sus idolatrías. Es verdad que donde emos tenido algunas pesadumbres es en el reyno donde ellos están muchos, porque, como dixe arriba, donde ellos no pueden acudir no se les da tanto que vaiamos, pero la respuesta que ellos dan todo lo comprehende porque dizen que son parrochos, y la misma razón en todos los reynos donde ellos estuvieren repartidos. Y assí lo que temo es no saquen algo si nos durmimos, que nos pese.

\section{1 de setembre de 1621: Carta a fra Joseph Orfanell des de la presó de Vomura ${ }^{91}$}

[f.247] Desde la cárcel de Vomura me escrivió una carta que llegó a mis manos por modos tan incógnitos, que con aver yo echo vivas diligencias por saber quien la avía traydo, ya más pude hallar rastro, ni persuadirme otra cosa, sino que el santo avía alcançado de Dios la traxesse algun ángel. Y la carta está en mi poder toda de su mano y papel de Indias. $\mathrm{Y}$ es del tenor siguiente.

«Al Padre fr. Joseph Orfanell Religioso descalço de la Orden de S. Francisco. Guarde Nuestro Señor. En el Convento de S. Juan de la Ribera de la Ciudad de Valencia. Es de Japón.

Jhs. Sea con V.R. y de mucho de su santo amor y gracia. Estando ya con el papel puesto y pluma en la mano para escrivir y despedirme de V.R. llegó de ventura (porque ay gran rigor que no entren cartas, y al que la metió le cortaran la cabeça si se supiera) a esta cárçel una de V.R. de 25 de Março 1618, con la qual por aver llegado a tal punto me consolé mucho por saber nuevas de V.R. y de los demás parientes y conocidos, y del 
gran servicio que V.R. haçe a Dios en acudirles y ayudarles, cuyo premio tendra V.R. muy grande en el cielo. Yo a cinco meses que estoi preso en compañia de otros onze sacerdotes, dellos son de S. Francisco, y de la Compañia, y de S. Domingo somos seis, y algunos que ha ya tres y quatro años que lo estan. Ay también un clérigo, y muchos Japones, que por todos somos 30, todos presos por la fe y predicación del Santo Evangelio. Estamos en una cárçel muy rigurosa y estrecha, y la comida tal, que me espanto como no se mueren algunos, pero no la trocáramos por todas las delícias y regalos del mundo, ni esta estrechura por los anchos palacios de los reyes y monarcas de la tierra por ser por tan buen Señor, a quien rogamos no nos saque de aquí sino para dar la vida por su santo nombre. A mí me prendieron el dia del Evangelista S. Marcos deste año 21, andando por varias partes deste Japón administrando a esta christiandad, y ayudándole con mi cornadillo. Y aunque por mis grandes pecados merecía mil infiernos, el Señor por su infinita misericordia fue servido de cruzar las manos, porque ayer tuvimos nuevas de como venían ya con mucha gente de armas para matarnos y sacarnos de la triste carçel deste cuerpo. Y assí para que a V.R. le constasse y hiçiesse saber tan dichosas nuevas a nuestra madre si fuere viva, y demás parientes, y conocidos, me pareció escrivir estos ringlones, aunque yran muy a la ventura; porque aunque e podido escrivir, no sé si podré entregar la carta, porque son tantas las guardas, que ningun christiano se osa llegar. Y la de V.R. fue gran ventura entrar a noche, porque se animó un buen christiano, porque llovía, y los guardas estavan descuidados, y la metió, pero allá va a la ventura.

Huelgo en el alma que vivan todos tan en temor de Dios y desengañados de lo que es este mal mundo. V.R. de mi parte se sirva darles muchas saludes, y que yo no me olvidaré dellos (Si el Señor nos hiziere la gran merced que esperamos) quando me vea en su divina presencia. Y en particular ruego mucho procuren servir a Dios muy deveras. A N. y N. etc. a quien tengo y llevo en el alma.

En la ciudad de Nangasaqui ay al presente en las cárceles públicas algunos christianos en cuyas casas hallaron algunos de los religiosos que estamos presos, a los quales parece que los quemarán vivos, como hizieron ahora dos años a otros cinco por la misma causa. Otros presos ay tambien por la fe en aquella ciudad, que todos an de morir. A nosotros entendemos que nos matarán en secreto, porque no se junten los christianos; que si lo saben, vendrán infinitos. Aquí estamos esperando lo que el Señor ordenare [f. 247v] de nosotros, como hijos que somos de la Iglesia, ciertos que quanto más nos afligieren estos gentiles, mayor bien nos harán. Los años passados murieron muchos santos mártyres, entre los quales huvo algunos religiosos, dos de S. Francisco, uno de S. Agustín, otro de la Compañia, y otro de nuestra Orden, de todo lo qual an ydo relaciones a las quales me remito. Y porque estoi de prissa, no más. Sino que nuestro Señor guarde a V.R. y haga un gran santo; como yo deseo, y nos junte en el cielo. Amén. Desta cárçel de Vomura y Setiembre día del glorioso Apostol S. Matheo deste año 1621. Siervo de V.R. Fray Jacinto Orfanell. 


\section{5 d'agost de 1622: Carta a Fray Diego Collado. Señor Salmantino ${ }^{22}$}

[f.125] Copia de algunas cartas que estos santos mártyres escrivieron a su Vicario provincial y otros desde la cárcel donde estavan presos para ser martirizados.

He de advertir que estas cartas yo mesmo las e copiado de sus propios originales. Y fue la ocasion, que el Padre fray Diego Collado (que es a quien los santos mártyres escrivían, y era Vicario provincial dellos, y de los demás frayles de Santo Domingo que estavan en Japón) fue desde Japón a Roma para dar razón al Pontífice Summo de los dichos martyrios, y de la contradición que los Padres de la Compañía hazían allá a los demás religiosos de otras Ordenes, conforme se contiene en el Memorial, que el proprio fray Diego Collado me dexó copiar, que está en el fol. III pag. 2, juntamente con la relación de la persecución de la christiandad en el Japón, y de su causas, que se hallará en el fol. 115 pag. 2. Y de Roma vino a España para dar razón a su Majestad de lo proprio, y quando passó por esta ciudad, estuvo algunos días en este convento y assí tuve yo ocasión para copiar los dichos memoriales, y estas cartas, que se siguen, llevándose él los proprios originales por relíquias.

«Al Señor Salmantino guarde Nuestro Señor. ${ }^{93}$ Iesus sea con V.m. Señor nuestro amo, y pague tantes charidades como nos ha echo, y mucho mas el cuydado de acudir a los santos presos de essa ciudad y de Yagami. Poco falta, per viscera Jesu Christi no los dexe V.m. hasta ver concluído su' ${ }^{94}$ negocio, que ellos lo pagarán desde el cielo; ni afloxen un punto en acudir a esta perseguida christiandad, que el premio a de venir de buena mano. Las nuevas destos días emos recebido como cosa del cielo: y parece que son ciertas, porque ha ya cerca de un mes que nos han doblado las guardas, las quales de noche y de día estan con gran vigilancia, y assí de hora en hora estamos esperando el dichoso plazo, el qual si el Señor es servido que llegue, y hiziere tan gran merced y misericordia con este miserable y abominabilíssimo pecador, esté V.m. cierto que no seré como el copero de Faraón. Lo mismo digo al señor Vázquez y Castellet, a quién no escrivo, pero si huviere lugar después, lo haré con mucho gusto, y doy muchas gracias de como an acudido al consuelo de nuestro casero. Y a todos suplico ${ }^{95}[\mathrm{f} .125 \mathrm{v}]$ si llegare ésta antes que nos despachen, que me encomienden a Dios, que tengo mucha necessidad. No nos dezían las nuevas, la muerte que nos han de dar, si de cruz, fuego, cuchillo, etc., pero sea la que fuere, y el demonio pudiere inventar, estamos muy aparejados con el ayuda del Señor a padecerlo todo por su santo nombre y fe, que es la que nos tiene enseñada la Santa Madre Iglesia Romana, en cuya crehencia hemos vivido, y ahora murimos con sumo contento y alegría. Y concluye diziendo: Y confiado, no más, mi charíssimo compañero y padre, sino que el Señor nos junte en el cielo Amén. Desta cárcel de Vomura y Agosto 25 de 1622. Siervo indigno de V.m. Fr. Jacinto Orfanel.

92. UB-R, Ms. 1008-1010, vol. II, f. 125-127v. També reproduïda a Orfanel, Jacinto y Diego Collado, Historia eclesiástica..., cit., f. 164-164v, 1623 i al Sumario..., cit., UB-R, Ms. 1008-1010, vol. II, f. 250v.

93. Nota al marge: llama Salmantino al Padre fray Diego Collado su Vicario general, y en la carta le llama nuestro amo por dissimular, y le trata de V.m.

94. nog ratllat.

95. Nota al marge: Vazquez y Castellet eran otros dos religiosos que por dissimular los llama señor. 